\title{
Quality-improving and cost-reducing strategic alliances
}

\author{
Fabio Di Dio ${ }^{1} \cdot$ Luca Correani $^{2}$
}

Received: 3 December 2018 / Accepted: 29 February 2020 / Published online: 12 March 2020

(c) The Author(s) 2020

\begin{abstract}
We develop a two-stage Salop-type model to examine quality-improving and process innovation alliances in an oligopolistic context. In the first stage, a network of alliances among firms is assumed while in the second stage firms set prices, product quality and cost-reducing process innovation. We find that quality-improving networks tend to be denser than networks characterized by process innovation sharing, while the quality effort decreases with the number of connections. Furthermore, link formation is welfare improving if both absorptive capacity and quality spillovers are sufficiently small. Although the empirical evidence on cooperation in R\&D is fragmentary it nonetheless supports most of the theoretical predictions. We also formulate some variants of the model to assess the robustness of the previous results.
\end{abstract}

Keywords Networks $\cdot$ Salop model $\cdot$ Process and product innovation

JEL Classification E27 · E60 · Q40 · Q58

\section{Introduction}

What are the conditions under which firms undertake quality-improving and costreducing strategic alliances? To what extent will they share Research and Development $(\mathrm{R} \& \mathrm{D})$ knowledge? How much link formation is welfare improving in presence

\footnotetext{
The views expressed are purely those of the author and may not in any circumstances be regarded as stating an official position of the European Commission.

Fabio Di Dio

fabio.di-dio@ec.europa.eu

http://fabiodidio.altervista.org/index.html

Luca Correani

correani@unitus.it

1 European Commission, DG Joint Research Centre, Directorate B-Growth and Innovation, Unit B1-Finance and Economy, Via E. Fermi, 2749-21027 Ispra, Varese, Italy

2 Department of Economics and Business, University of Tuscia, Via del Paradiso, 01100 Viterbo, Italy
} 
of absorptive capacity and quality spillovers? In this paper we address these questions by using a theoretical model to shed light on the relationship between strategic R\&D investment and networks of collaborations aimed at sharing R\&D knowledge.

More specifically, we consider a two-stage model with $N \geq 2$ firms symmetrically distributed on the Salop-type circle (1979), a popular alternative of Hotelling's linear city model. In the first stage, a network of alliances among firms is posited. In the second stage, firms choose prices, product quality and process innovation aimed at reducing production costs. In this context we also assume absorptive capacity which is the firm's ability to recognize and assimilate knowledge from competing firms by means of R\&D investment. Since absorptive capacity depends greatly on firm-related technological knowledge, investments in R\&D are therefore central to the firm strategy.

The demand side corresponds to the one in the traditional Hotelling set-up, but the circular city model allows us to focus the analysis on the symmetric equilibrium in which all firms charge the same price, product and process R\&D efforts. In this way, the model is able to capture knowledge spillovers driving the voluntary exchange of information among vertically and horizontally differentiated firms being the result of direct interactions (links) with each other for specific business objectives. However, even with symmetry, each firm's strategic behaviour varies depending on whether the collaborating firm is a neighbour or not. This interesting implication stems from the fact that the demand for a generic firm $i$ directly depends on its neighbour strategies. We also assume that cooperation between firms aimed at both lowering their own marginal costs of production (process innovation) and sharing product quality investments (product innovation) (see Lambertini and Mantovani 2009).

This paper contributes to the growing strand of literature dealing with R\&D agreements among vertically and horizontally differentiated firms. The growing interest for these issues basically reflects the policy relevance of these questions, namely how networks of collaborations among firms are capable of turning R\&D investments into productivity and welfare improvements. Indeed, in recent years a rapidly growing strand of theoretical and empirical literature has been focusing on R\&D agreements among vertically and horizontally differentiated firm. ${ }^{1}$

However, the empirical literature related to the theoretical underpinnings developed in the paper suffers from the lack of a shared and official source of information, namely the available information is scanty and mostly made up of case studies. So we might rely on case studies or databases that only partially cover our research topic. Broadly speaking, the available evidence, though fragmentary, supports most of our theoretical conclusions.

Our key findings are as follows.

\footnotetext{
1 Paier and Scherngell (2011) provides some empirical evidence in favour of Salop-type models involving networks of collaborations. They show that proximity and technological similarity play a key role in innovation networks. Also, their results indicate that it is most likely that firms choose partners that are similar relative to technological knowledge and expertise.
} 
First, quality effort (product innovation) decreases with the number of connections whereas increases in presence of process innovation. As a result, cooperating firms set a lower product quality to limit partner advantages at their expenses. Nonetheless, absorptive capacity induces firms to increase their own effort in process innovation as the number of cooperative links increases. This effect, however, is mitigated by a lower spillover rate, meaning that higher spillovers will generate a higher incentive for collaboration and for undertaking R\&D investments. Nonetheless it is worth noticing that with product innovation the opposite is true, that is higher spillovers generate a lower incentive to collaborate. Jaffe (1986) finds that the incentive to cooperate is greater in sectors where spillover is larger. Large-spillover industries, typically, are telecommunications, chemicals and electronics. Vonortas (1994) finds significantly more joint ventures in large- and medium-spillover industries reporting that telecommunications and computer software ranked first both in number of research joint ventures and in membership. More recently, Lopez (2008), using Spanish data on manufacturing firms, has found that larger spillover and more effective strategic methods of appropriating the returns from innovation make R\&D cooperation more probable. To be sure, these empirical works show some general tendencies, but the variety of results nevertheless confirm that to evaluate R\&D cooperation it is important to include the effects of spillovers and possibile freeriding issues that may come from it. Indeed, the variety of spillovers that a cooperation may give rise to, renders a case-by-case approach desiderable. As an example, in cooperating for developing a new computer, the partners may easily assess the contribution of each member according to the particular component to develop, so that free-riding problems may be limited. On the contrary, in a network to develop a new vaccine it is harder to assess each member know-how and contribution, so that free-riding issues are more probable.

Second, quality-improving networks are denser relative to those driven by process innovation. In this case, firms could increase their product quality simply forming agreements, without bearing the inherent costs. Hence, firms will reduce their effort and increase cooperation agreements, giving rise to denser networks.

Among others, Tomasello et al. (2016) study the evolution of R\&D networks and the process of alliances formation in several manufacturing sectors over 24-year period (1986-2009). They show that the dynamics of R\&D networks has been characterised by two distinctive phases: a rise phase (from 1986 to 1997) where alliances gave rise to dense network structures and a fall phase (from 1998 to 2009) where networks become more sparse and fragmented. However, in both phases, network size is higher in high-tech industries, such as Pharmaceuticals, Computer software and electronic components, which are characterised by the constant need to generate new products. Differently, medium-tech and low-tech industries like Aircrafts and parts and Motor vehicles are mostly involved in process innovation and exhibit a lower level of R\&D agreements. Figure 1 shows the evolution of network size (number of edges) for five industrial sectors characterised by different technological content.

Third, link formation is welfare improving if both absorptive capacity and quality spillovers are sufficiently small. Put it different, an increasing number of connections lowers product quality but this effect is lessened by small spillovers 


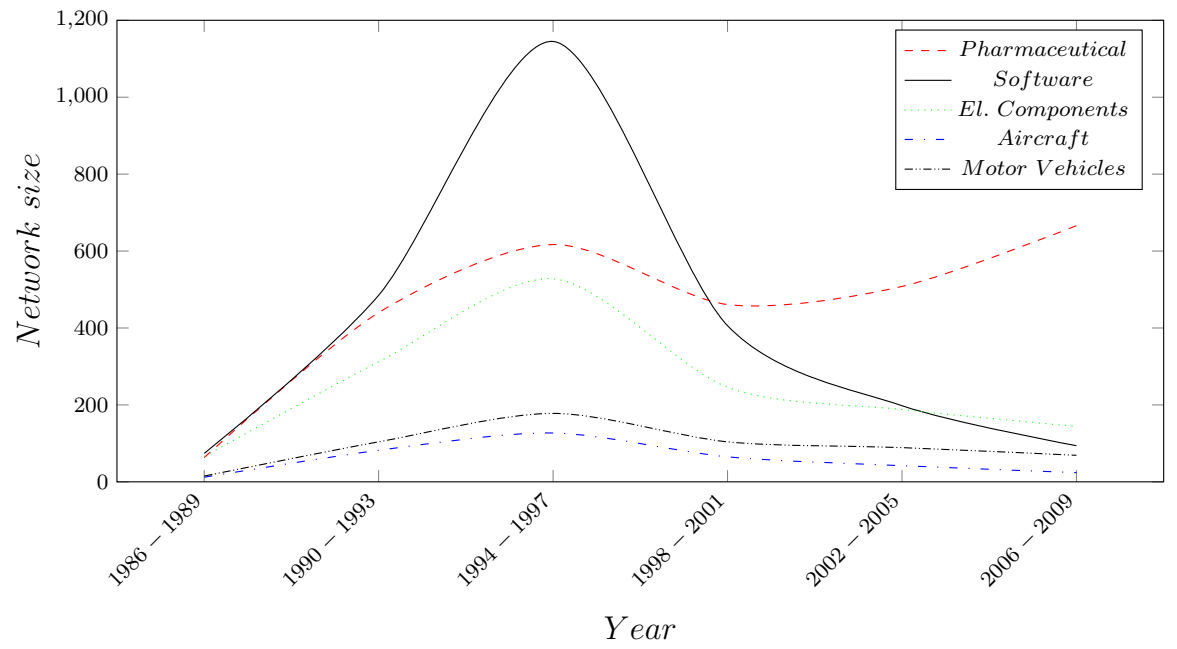

Fig. 1 Network size for sectoral R\&D networks Source: Tomasello et al. 2016

which induce firms to increase quality and then consumer surplus. The model allows us to draw some rather strong conclusions relative to welfare which support the view that all the types of R\&D collaboration can be welfare-improving for appropriate choices of degree of spillover and product differentiation.

Fourth, we find a general tendency to under-connection relative to social welfare when link formation is driven by process innovation; on the contrary, we observe that networks of alliances tend to be over-connected as compared to the social optimum if quality-improving alliances prevail. This result is a consequence of how innovation induces firms to balance benefits and risks associated to networking. On the one hand, process innovation makes firms able to learn from partners becoming more competitive. As a consequence, firms are induced to reduce both connections and their own effort with the aim to limit competition and increase profits. On the other hand, in presence of product innovation networks there is a high risk of free riding, namely firms can increase their own product quality without investing in quality. Therefore, firms will tend to limit their quality effort and to increase the number of cooperative links, giving rise to over-connected networks.

Given these results, every policy aimed at stimulating quality-improving and costreducing strategic alliances should be able to address the possible trade-off arising from the presence of product and process innovation. In this context, policy-makers should carefully strike a balance between two opposing forces: on the one hand, policies leading to enhance process innovation networks may be self-defeating, namely they could create incentives to reduce connections as a result of firm ability to learn from others; on the other hand, policies promoting investments in product quality should also prevent opportunistic (free-riding) behaviours.

The remainder of the paper is structured as follows. In Sect. 2 we discuss the related literature. In Sect. 3 we introduce the model. In Sects. 4 and 5 we present 
and discuss the main results. In Sect. 6 we consider some variants of the model. Section 7 concludes.

\section{Related literature}

In what follows we discuss the results and relate them to the findings of the literature on network formation, pointing out the key elements of differentiation between our analysis and previous works. However, the literature studying network formation and $R \& D$ investment is quite large and a complete survey is beyond the scope of this paper. Hence, we will only briefly refer to a few of those studies addressing the consistency of our results with them.

The first attempt to examine collaboration networks among firms located in Salop's circular city is by Okumura (2012). ${ }^{2}$ He describes a two stage game in which firms first form bilateral collaboration links and then engage in price competition. Focusing on symmetric networks, he shows that firms tend to form a link with more distant firms if the cost-reducing effects are the same. Differently from Okumura (2012), we assume that in the second stage firms simultaneously choose prices, product quality (product innovation) and cost reducing process innovation. As a result, a link between two firms entails the voluntary exchange of information as part of the trade. Nonetheless, differently from Okumura (2012), our model assumes that knowledge from collaboration crucially depends on two key features. First, the presence of knowledge sharing and process innovation. In particular, following Kamien and Zang (2000) and Leahy and Neary (2007) approach, we assume that firm's marginal cost reduction depends on $R \& D$ spending coupled with a fraction of the partners' R\&D spending. Second, the introduction of knowledge sharing and product innovation. Following Symeonidis (2003) and Deroian and Gannon (2006), we suppose that every firm's quality effort spills over its partners. Differently, Okumura (2012) assumes that marginal costs are linearly declining in the number of links but he does not consider endogenous R\&D efforts.

Goyal and Moraga-Gonzalez (2001) contribute to this literature by considering a Cournot oligopoly where identical firms have the opportunity to form pair-wise collaborative links to share R\&D knowledge concerning a cost reducing technology. Their key finding is that in different (respectively homogeneous) product markets, $R \& D$ investments are increasing (respectively decreasing) in the number of alliances. Moreover, a second important result pertains the incentive to form alliances; in particular, focusing on regular networks, they show that the complete network is uniquely stable and efficient in the absence of firm rivalry.

\footnotetext{
${ }^{2}$ In his seminal paper Bloch (1995) analyses the formation of associations of firms in a two stage oligopoly game. Group formation is modelled in terms of a coalition structure which is a partition of the set of firms. Differently, our model considers two-player relationships and allows for cooperative agreements that are nonexclusive. A different and interesting application of the circular city is by Heikkinen (2014) who extends Salop's model to the study of network externalities.
} 
Deroian and Gannon (2006) propose an interesting extension of Goyal and Moraga-Gonzalez (2001) model, studying rival firms' incentives in qualityimproving R\&D networks. In their model, firms can form alliances in order to share R\&D efforts and benefit from the resulting increased quality level. They show that quality investment decreases with the number of partners, networks are over-connected compared to the social optimum and the profit maximizing number of links is non-monotonic with respect to the inverse measure of horizontal product differentiation.

Goyal and Joshi (2003) extend the analysis to Bertrand oligopoly. In the case of price competition among the firms, they observe a conflict between stability and efficiency in networks. The unique stable network is the empty one, whereas social welfare maximization requires a connected network. In a similar setting (with both quantity and price competition), Goyal et al. (2008) study a network formation model in which individual firms carry out in-house research on core activities and undertake bilateral joint projects on non-core activities with other firms.

Along these lines Correani and Di Dio (2017) develop a model to examine the link formation and the stability of networks in a Hotelling-type oligopoly. They show that with high vertical but low horizontal differentiation, strategically stable networks are incomplete (namely, empty, partially connected or star networks) because of the high costs of forming links borne by high-quality firms and the more severe price competition. On the contrary, when firms feature low vertical differentiation but high horizontal differentiation, they benefit from forming cooperation agreements and denser networks are thus pair-wise stable. Moreover, when link costs are large, stable networks are not socially efficient. Also, Correani et al. (2014) study network formation in a symmetric Cournot oligopoly assuming that each firm can increase its ability to learn from other firms by raising its $R \& D$ expenditure, according to the theory of absorptive capacity.

Although closely related to the literature our paper departs from it in some respects. First, we consider both endogenous product and process R\&D investments and analyse their effects on network architectures. Second, the Salop framework allows us to combine horizontal product differentiation with the analysis of symmetric equilibria which are not a workable solution in the traditional Hotelling model (see Correani and Di Dio 2017). Finally, following Economides (1993) we augment the Salop model to include quality differentiation; this allows us to study cooperation in both product and process innovation without losing analytical tractability.

About the question of how to include process and product innovation in a model, the answer is debated. The common view in the literature is that product innovation in most cases precedes process innovation (see Klepper 1996). However, many firms change their organization so as to be able to carry out both process and product innovation at the same time. On this line of research, Adner and Levinthal (2001) argue that firms finance product and process innovation simultaneously because technology changes depend on the interaction between technology development and consumer preferences.

In our model firms are assumed to choose their own prices and investments simultaneously whereas in traditional models of network formation (see for instance 
Goyal and Moraga-Gonzalez (2001), Deroian and Gannon (2006)) firms invest in $\mathrm{R} \& \mathrm{D}$ at an early stage of the game then fix price at a later stage. ${ }^{3}$

Nonetheless, it is worth noticing that we complement the current literature deriving results for goods that are substitute. Only recently, Mantovani and Ruiz-Aliseda (2016) have examined a game-theoretic model in which firms can collaborate with producers of complementary goods to enhance the quality of the systems formed by their components. They show that R\&D collaboration among complementors increases welfare but may make firms worse off. Moreover, this result may holds regardless of whether collaboration ties are exclusive or not. In this respect, interesting empirical evidence is shown in Adner and Kapoor (2010) that examine vertical relationships among producers of complementary goods as a strategy for managing technological interdependence changes and improving interoperability of their respective products. ${ }^{4}$

\section{The model setup}

In this Section we present the main blocks of the model. We first introduce the preferences (demand and supply side); then we define product differentiation and R\&D investment. Finally, we account for the timing of the moves. Following Economides (1993) we assume that firms choose their own price and investments simultaneously at the final stage of the game. It is worth mentioning that an alternative way to analyse network formation among differentiated firms is the so called 'spokes models' that basically are an extension of the Hotelling game (see Chen and Riordan 2007; Mantovani and Ruiz-Aliseda 2016). Nonetheless, as Reggiani (2014) points out, the spokes model implies that neighbouring effects are not relevant to firms whereas in our model we focus also on the role of firms' proximity in network formation. This is a very important point given that, as Paier and Scherngell (2011) have pointed out, $\mathrm{R} \& \mathrm{D}$ networks are significantly affected by thematic and geographical proximity.

\subsection{The industry}

Let us suppose that $N \geq 2$ firms are equidistantly located on a circle of circumference one and consumers are uniformly distributed on that circle (Salop 1979). Each firm produces differentiated goods and consumers buy at most one unit of these goods with the aim of maximising the following utility function:

\footnotetext{
3 The simultaneity of moves allows us to impose symmetry from the beginning, so as to streamline the work to find an analitical solution in presence of product and process innovation. To be sure, alternative hypotheses about the timing, such as sequential moves, are also possibile. Nonetheless, in this case symmetry among firms cannot be imposed at the initial step of the game. The process to find a solution thus will be more difficult, also considering the presence of quality and process effort as choice variables.

4 Some further theoretical contributions are in Baumol (2001) and Tomasello et al. (2016). Besides, Okumura (2012) and Correani and Di Dio (2017) develop, respectively, a Salop and Hotelling model to study R\&D networks formation in a context of product differentiation.
} 
Fig. 2 Portion of Salop circumference

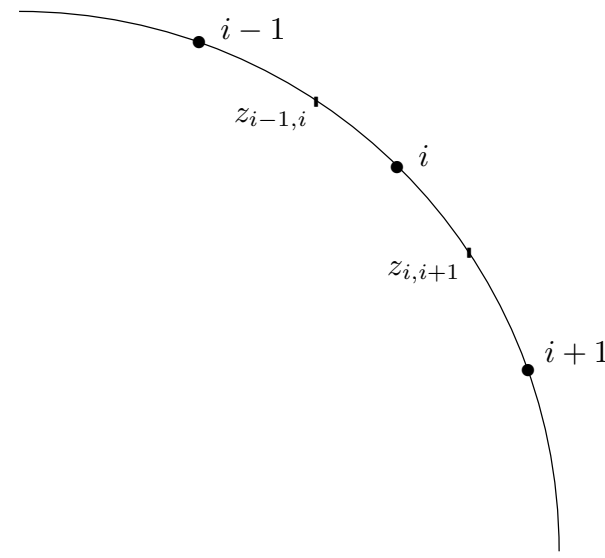

$$
u=\left(r+r_{k}\right)-\tau\left|l_{k}-z\right|-p_{k},
$$

where $l_{k}=\frac{k}{N}$ denotes the location of firm (product) $k \in\{1, \ldots, i-1, i, i+1, \ldots, N\}$ on the Salop's circle, whereas $z$ is the location of consumer. The term $\left(r+r_{k}\right)$ indicates the willingness to pay depending on a constant $r$, which is taken to be the same across products, and the quality of variety $k, r_{k}$. Without loss of generality, we assume that $r$ is sufficiently large such that the consumer purchases. Finally, $\tau>0$ is the transportation cost. The consumer $z_{i, i+1}$ who is indifferent between goods $i$ and $i+1$ is defined by

$$
z_{i, i+1}=\frac{2 i+1}{2 N}+\frac{p_{i+1}-p_{i}}{2 \tau}+\frac{r_{i}-r_{i+1}}{2 \tau},
$$

whereas, by analogy, the consumer who is indifferent between goods $i$ and $i-1$ is as follows:

$$
z_{i-1, i}=\frac{2 i-1}{2 N}+\frac{p_{i}-p_{i-1}}{2 \tau}+\frac{r_{i-1}-r_{i}}{2 \tau}
$$

Given that firm $i$ attracts consumers located between $z_{i-1, i}$ and $z_{i, i+1}$, we compute the demand for firm $i$ as $z_{i, i+1}-z_{i-1, i}$ and obtain:

$$
Q_{i}=\frac{1}{N}+\frac{p_{i+1}+p_{i-1}-2 p_{i}}{2 \tau}+\frac{2 r_{i}-r_{i+1}-r_{i-1}}{2 \tau} .
$$

See Fig. 2 for its graphical counterpart.

\subsection{Product differentiation, absorptive capacity and spillovers}

Firms invest in R\&D in order both to increase product quality and to reduce their marginal cost (process innovation): these efforts are denoted, respectively, by $\theta_{i}$ and $x_{i}$. The effort profile in the industry is thus defined as $E=\left\{\left(\theta_{1}, x_{1}\right),\left(\theta_{2}, x_{2}\right), \ldots,\left(\theta_{N}, x_{N}\right)\right\}$. Prior to competing in the market, firms can form alliances (pair-wise collaborative 
links) with other firms, in order to share $R \& D$ efforts and benefit from the resulting reduced marginal costs and increased quality. Let $N_{i}$ indicate the set of firms linked with firm $i$. Following Symeonidis (2003) and Deroian and Gannon (2006), the function linking firm $i$ 's quality to product R\&D efforts $\theta_{i}$ and $\left\{\theta_{k}\right\}_{k \in N_{i}}$ is given by

$$
r_{i}=\varepsilon\left(\theta_{i}+l_{\theta} \sum_{k \in N_{i}} \theta_{k}\right)^{\beta},
$$

with $0 \leq \beta \leq 1$ and $\varepsilon \geq 0$. The parameter $l_{\theta} \in[0,1]$ denotes the extent of technological spillovers whereas $\varepsilon$ is an index of technological opportunity in the industry. Finally, $\beta$ is a measure of the elasticity of the quality index $r_{i}$ with respect to firms' quality investments. Observe that this formulation implies decreasing returns to R\&D efforts produced by the partners.

Differently, to model the effects of process $R \& D$ on firms' marginal costs we follow the formulation proposed by Kamien and Zang (2000) and Correani et al. (2014). Precisely, we assume that firm $i$ 's marginal cost reduction is represented by

$$
X_{i}=x_{i}+(1-\delta) x_{i}^{\delta} l_{x}\left(\sum_{k \in N_{i}} x_{k}\right)^{1-\delta},
$$

where $l_{x} \in[0,1]$ is an exogenous rate of spillovers. With this formulation we take into account the idea that the $R \& D$ process generates new knowledge but that it also enhances the firm's ability to learn from others, the so-called absorptive capacity. The term $0 \leq \delta \leq 1$ represents the firms' R\&D approach. When $\delta=1$, firms $\mathrm{R} \& \mathrm{D}$ approach is too specific and they cannot receive positive spillovers from their partners because the information they provide is irrelevant to them. On the other extreme, $\delta=0$ implies a totally non-specific R\&D approach and every firm has the highest absorptive capacity for any level of its R\&D investment. It is worth noticing that this formulation excludes the possibility of manna from heaven given that firms cannot benefit from partner R\&D spillovers without engaging in process R\&D itself. Both formulations (5) and (6) capture the public good nature of knowledge.

At this point we are able to define the profit function of the generic firm $i$ as

$$
\pi_{i}=\left(p_{i}-c_{i}\right) Q_{i}-\gamma_{x} \frac{x_{i}^{2}}{2}-\gamma_{\theta} \frac{\theta_{i}^{2}}{2},
$$

where, as in Goyal and Moraga-Gonzalez (2001), it is assumed that the costs of individual R\&D efforts $\theta_{i}$ and $x_{i}$ are quadratic, with $\gamma_{\theta}>0$ and $\gamma_{x}>0$. Furthermore, according to (6), the effective marginal cost is of the form $c_{i}=c-X_{i}$, where $c$ is the constant marginal production cost of firms.

\subsection{Timing of moves}

We adopt a two-stage game. In the first stage, firms are engaged in pair-wise alliances (links), in order to share product and process R\&D knowledge. For the sake of 
simplicity, the link formation between two firms is assumed to be costless. In the second stage, firms simultaneously choose R\&D efforts $\theta$ and $x$, and compete à la Bertrand fixing price $p$.

The pair-wise alliances formed at stage 1 can be described as a non-directed graph $g$ in which nodes and edges are represented by, respectively, firms and R\&D alliances. Let $N_{i}(g)$ indicate the set of firms linked with firm $i$ in the graph $g$ and $m_{i}(g)$ denote the cardinal of $N_{i}(g)$, or firm $i$ 's degree. A network $g$ is regular (symmetric) if $m_{i}(g)=m$ with $m \in\{0, \ldots, N-1\}$ for all $i \in N$, namely a network is said regular or symmetric if all firms have the same number of links. In order to ensure a regular network of every possible degree we must assume that $N$ is even. In the empty network firms' degree is $m=0$ whereas the complete network is such that $m=N-1$.

\section{Results}

In this Section we present the main results. First, we find the conditions for the positivity and concavity of firms' profits (Proposition 1 and Claim 1 in Sect. 4.1). Second, we study the network degree under which each firm maximises its profits. The main results are in Propositions 2 and 3 of Sect. 4.2. Finally, by taking advantage of the previous results we seek out welfare implications of the network formation (Propositions 4-5 of Sect. 4.3).

\subsection{Nash equilibrium and firms' behaviour}

As usual in the literature on network formation, we focus on regular, namely symmetric networks. Moreover, following Deroian and Gannon (2006), we analyze Nash-equilibria in the second stage.

A final profile of R\&D efforts and prices $E^{*}=\left\{\left(\theta_{1}^{*}, x_{1}^{*}, p_{1}^{*}\right), \ldots,\left(\theta_{N}^{*}, x_{N}^{*}, p_{N}^{*}\right)\right\}$ is said to be a Nash-equilibrium on the graph $g$ if $\pi_{i}\left(\left(\theta_{i}^{*}, x_{i}^{*}, p_{i}^{*}\right), E_{-i}^{*}, g\right) \geq \pi_{i}\left(\left(\theta_{i}, x_{i}, p_{i}\right), E_{-i}^{*}, g\right)$ for all $\left(\theta_{i}, x_{i}, p_{i}\right) \in \mathfrak{R}_{+}^{3}$ and for all $i \in N$. Thus, we can define a symmetric Nash equilibrium on the regular graph $g$ of degree $m$ as a final profile $E^{*}(m)$ with $\theta_{i}^{*}=\theta^{*}, x_{i}^{*}=x^{*}$ and $p_{i}^{*}=p^{*}$ for all $i \in N$.

To calculate the Nash equilibrium $E^{*}(m)$ we proceed by backward induction, maximising profit function (7) with respect to $p_{i}, \theta_{i}$ and $x_{i}$, under conditions (5) and (6). The results are summarized in the following first order conditions:

$$
Q_{i}-\frac{p_{i}-c_{i}}{\tau}=0
$$




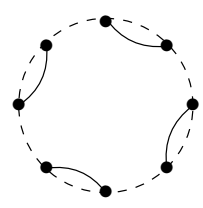

(a) $0_{[1]}$

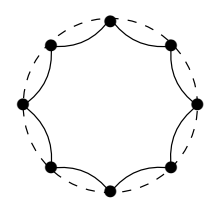

(b) $0_{[2]}$

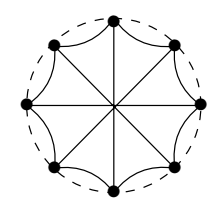

(c) $1_{[2]}$

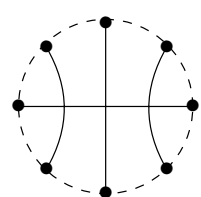

(d) $1_{[0]}$

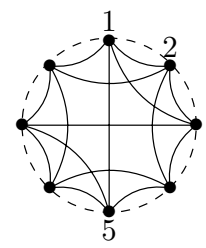

(e) $2_{[2]}$

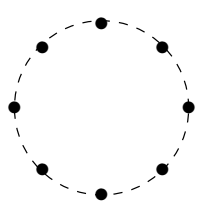

(f) $0_{[0]}$

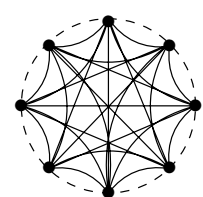

(g) $5_{[2]}$

Fig. 3 Some network structures with 8 firms

$$
\begin{gathered}
\left(p_{i}-c_{i}\right)\left\{\frac{\varepsilon \beta}{\tau}\left[\theta_{i}+l_{\theta} \sum_{k \in N_{i}} \theta_{k}\right]^{\beta-1}-\frac{\varepsilon \beta}{2 \tau}\left[\theta_{i+1}+l_{\theta} \sum_{k \in N_{i+1}} \theta_{k}\right]^{\beta-1} l_{\theta} s_{i, i+1}+\right. \\
\left.-\frac{\varepsilon \beta}{2 \tau}\left[\theta_{i-1}+l_{\theta} \sum_{k \in N_{i-1}} \theta_{k}\right]^{\beta-1} l_{\theta} s_{i, i-1}\right\}-\gamma_{\theta} \theta_{i}=0 \\
Q_{i}\left[1+(1-\delta) \delta x_{i}^{\delta-1} l_{x}\left(\sum_{k \in N_{i}} x_{k}\right)^{1-\delta}\right]-\gamma_{x} x_{i}=0
\end{gathered}
$$

where $s_{i j} \in\{0,1\}$ in (9) is a binary variable representing the pair-wise relationship between firms $i$ and $j$. It is equal to 1 if these two firms are linked, 0 otherwise. As Athey and Schmutzler (1995), conditions (9) and (10) state that the two types of innovation are complementary, meaning that increasing the optimal product innovation effort $\theta_{i}$ will imply an increase in the optimal process innovation effort $x_{i}$ and vice-versa. More formally, we make use of the Implicit Function Theorem applied to condition (10) in order to obtain $\frac{\partial x_{i}}{\partial \theta_{i}}=-\frac{\frac{\partial Q_{i}}{\partial \theta_{i}}\left[1+(1-\delta) \delta x_{i}^{\delta-1} l_{x}\left(\sum_{k \in N_{i}} x_{k}\right)^{1-\delta}\right]}{-(1-\delta)^{2} \delta x_{i}^{\delta-2} l_{x}\left(\sum_{k \in N_{i}} x_{k}\right)^{1-\delta} Q_{i}}$. Then, assuming symmetry the condition $\frac{\partial Q_{i}}{\partial \theta_{i}}>0$ will hold. We can thus conclude that $\frac{\partial x_{i}}{\partial \theta_{i}}>0$. Similarly, we apply the Implicit Function Theorem to condition (9) obtaining $\frac{\partial \theta_{i}}{\partial x_{i}}>0$.

Figure 3 shows six possible network architectures with $N=8$. According to Okumura (2012) we focus our attention on symmetric networks where all firms have the same number of links and, at the same time, choose homogeneous prices and 
investment levels, i.e. $p_{i}=p^{*}, \theta_{i}=\theta^{*}$ and $x_{i}=x^{*}$ for any firm $i$. It is worth noticing that in a Salop framework, a symmetric firm degree does not guarantee a symmetric Nash equilibrium. As an example, in the network (e) of Fig. 3, all firms have the same number of links but firm 1 collaborates with its furthest rival firm 5, whereas firm 2 does not. In this case, prices and investments of firms 1 and 2 are different.

More formally, the symmetric networks which guarantee the existence of a symmetric Nash equilibrium are those complying with the following definition:

Definition Let $d(i, j)$ be the distance between firms $i$ and $j$ such that $d(i, j)=d(j, i)=\min \{j-i, N-j+i\}$ with $j \geq i$. We consider all those symmetric networks such that if a firm $i$ is linked to a firm $j$ with $d(i, j)=\alpha$, then every firm $h \neq i$ is linked to a firm $k$ such that $d(h, k)=\alpha$.

In other words, the structure of collaborative links of each firm must be the same, even if we change firms' position. Observing Fig. 2, we note that, differently from the symmetric networks $(d)$ and $(e)$, all the other networks comply with this definition.

Thus, according to the above definition, we solve the model imposing symmetry, i.e. $p_{i}=p, \theta_{i}=\theta$ and $x_{i}=x$ for all firms, and rewrite conditions (8), (9) and (10) as follows:

$$
\begin{gathered}
p^{*}=\frac{\tau}{N}+\left\{c-\frac{1}{\gamma_{x} N}\left[1+(1-\delta) \delta l_{x} m^{1-\delta}\right]\left[1+(1-\delta) l_{x} m^{1-\delta}\right]\right\} \\
\theta^{*}=\left\{\frac{\varepsilon \beta}{\gamma_{\theta} N}\left(1+l_{\theta} m\right)^{\beta-1}\left[1-\frac{l_{\theta}}{2} s\right]\right\}^{\frac{1}{2-\beta}}, \\
x^{*}=\frac{1}{\gamma_{x} N}\left[1+(1-\delta) \delta l_{x}(\bar{m}+s)^{1-\delta}\right],
\end{gathered}
$$

where $s \in\{0,1,2\}$ in condition (12) is for the relationship between a generic firm and its neighbours. Moreover, to distinguish neighbours from other partners, we denote $m=\bar{m}+s$, with $\bar{m} \in[0, N-3]$ indicating the number of collaborating firms other than the neighbours. When $s=0$, then firms are not linked with their neighbours whereas if $s=1$ firms are linked with only one neighbour; finally with $s=2$ all firms have a link with both their neighbours.

Let us observe that the optimal quality investment $\theta^{*}$ decreases as the spillover rate $l_{\theta}$ increases, because of the free riding effect (see condition (12)). Differently, absorptive capacity brings about the optimal process investment $x^{*}$ to grow up with the spillover rate $l_{x}$ (see condition (13)).

Each network structure is identified by the expression $\bar{m}_{[s]}$ so that $(N-3)_{[2]}$ indicates the complete network (Fig. $3(g)), 0_{[0]}$ the empty network (Fig. $3(f)$ ), $0_{[2]}$ a partially connected networks where any firms is linked to its two neighbours (Fig. 3b) and so on. Moreover, we can use notation $\bar{m}_{[s]}$ to indicate the number of each firm's links, i.e. $\bar{m}_{[s]}=m=\bar{m}+s$. 
Proposition 1 In a regular network of degree $m$ the quality effort $\theta^{*}$ decreases with $m$ whereas $R \& D$ process investment $x^{*}$ increases with $m$.

Proof The result follows directly observing that $\frac{\partial \theta^{*}}{\partial \bar{m}} \leq 0, \frac{\partial x^{*}}{\partial \bar{m}} \geq 0 \forall \bar{m}, s$ and $\frac{\partial \theta^{*}}{\partial s} \leq 0$, $\frac{\partial x^{*}}{\partial s} \geq 0 \forall \bar{m}, s$.

This result entails that denser networks (increasing $m$ ) lead to lower equilibrium prices and product $R \& D$ investments (see conditions (11) and (12)) but higher process R\&D efforts (condition (13)). In other words, alliances allow firms to relax competition by reducing their own product quality. This result is in line with Goyal and Moraga-Gonzalez (2001), Deroian and Gannon (2006) and Correani et al. (2014) and stems from the fact that firms prefer to have a lower product quality in order to curb the risk of making the partners better at their expense. Differently, given the assumption of absorptive capacity for process R\&D investment, firms have the incentive to increase their effort $x^{*}$ as the number of partners increases. In line with Grunfeld (2003) and Correani et al. (2014), this positive effect is mitigated when the number of firms $N$ is large and the exogenous rate of spillover is small (see condition (13)).

Proposition 1 highlights the relevance of incorporating product and process innovation in the model and the trade-off arising from this feature. On the one hand a high risk of opportunistic behaviours (free riding) arises because firms can increase their quality even simply taking advantage of the quality effort of their partners. Thus, the higher is the number of links the lower is the investment in quality. On the other hand, process innovation is driven by absorptive capacity so that firms are encouraged to increase their own investment as the number of partners grows up.

Substituting equilibrium conditions (11), (12) and (13) into equation (7) we obtain the following reduced-form profit function:

$$
\begin{aligned}
\pi^{*}= & \frac{\tau}{N^{2}}-\frac{\gamma_{x}}{2}\left\{\frac{1}{\gamma_{x} N}\left[1+(1-\delta) \delta l_{x} m^{1-\delta}\right]\right\}^{2} \\
& +-\frac{\gamma_{\theta}}{2}\left\{\frac{\varepsilon \beta}{\gamma_{\theta} N}\left(1+l_{\theta} m\right)^{\beta-1}\left[1-\frac{l_{\theta}}{2} s\right]\right\}^{\frac{2}{2-\beta}} .
\end{aligned}
$$

Let us observe that link formation entails negative externalities (lower profits) if it concerns process innovation sharing whereas positive externalities arise from product quality agreements. This is a central point for the study of the relationship between private and social incentive to form networks of collaboration. As it will be clearer later (Sect. 4.3 ), the predominance of negative externalities will induce firms to generate under-connected networks.

The following Claim sets the (sufficient) conditions for parameter $\tau$ to support the positivity and concavity of firm's profit function.

Claim 1 (positivity and concavity) Firm's profit function is both positive and concave with a maximum at $\left(p^{*}, \theta^{*}, x^{*}\right)$ if $\tau>\max \left[\tau_{1}, \tau_{2}, \tau_{3}\right]$, with $\tau_{1} \equiv \frac{N^{2}}{2 \gamma_{x}}+\frac{\varepsilon^{2}}{2 \gamma_{\theta}}$, 
$\tau_{2} \equiv \frac{\tilde{\pi}_{p \theta}^{2}}{-2 \pi_{\theta \theta}}$ and $\tau_{3} \equiv \frac{-B-\sqrt{B^{2}-4 A C}}{2 A}$ where $A=-2 \pi_{\theta \theta} \pi_{x x}, B=-\tilde{\pi}_{p x}^{2} \pi_{\theta \theta}-\tilde{\pi}_{p \theta}^{2} \pi_{x x}$ and $C=2\left(\tilde{\pi}_{p \theta} \tilde{\pi}_{\theta x} \tilde{\pi}_{x p}+\tilde{\pi}_{\theta x}^{2}\right)$.

Proof See Appendix.

\subsection{Optimal network degree}

We now proceed to investigate the degree $m^{*}$ under which firms maximize their profits. In the following Lemma we identify the (sufficient) conditions that allow us to reduce the number of first stage maximising profit networks to only three types of networks, namely the complete network $(N-3)_{[2]}$, the empty network $0_{[0]}$ and the partially connected network $0_{[2]}$, where each firm is linked only with its two neighbours.

Note that the profit function is a sequence because $m$ is a natural number ranging from 0 to $N-1$. However, as usual in the literature on oligopolistic networking, without loss of generality we can treat it as a continuous function and approximate $\pi^{*}(m+1)-\pi^{*}(m)$ by the derivative $\frac{\partial \pi^{*}}{\partial m}$ (see for example Deroian and Gannon 2006).

Lemma 1 For any set of admissible parameters:

1. if $\frac{\partial \pi^{*}}{\partial \bar{m}} \geq 0$ and $\frac{\partial \pi^{*}}{\partial s} \geq 0 \forall \bar{m}, s$, the complete network $(N-3)_{[2]}$ maximises firms', profits;

2. if $\frac{\partial \pi^{*}}{\partial \bar{m}}<0$ and $\frac{\partial \pi^{*}}{\partial s}<0 \forall \bar{m}$, s, the empty network $0_{[0]}$ maximises firms' profits;

3. if $\frac{\partial \pi^{*}}{\partial \bar{m}}<0$ and $\frac{\partial \pi^{*}}{\partial s} \geq 0 \forall \bar{m}$, s, the network $0_{[2]}$ maximises firms' profits.

Proof See Appendix.

It is worth noticing that the above Lemma only identifies first-stage profits maximising networks in the case that the profit function is either monotone increasing/ decreasing in both $s$ and $\bar{m}$ (isoprofit curves are decreasing) or increasing in $s$ for any $\bar{m}$ and decreasing in $\bar{m}$ for any $s$ (isoprofit curves are increasing).

We cannot exclude different results when profit function is maximised at an intermediate level $0<\tilde{m}<N-3$, as is stated in the following Lemma.

Lemma 2 Let us assume $\frac{\partial \pi^{*}}{\partial s} \geq 0 \forall \bar{m}$, s so that $s=2$ and define

$$
\begin{aligned}
& A(\bar{m})=\frac{1+(1-\delta) \delta l_{x} m^{1-\delta}}{\gamma_{x} N^{2}}(1-\delta)^{2} \delta l_{x} m^{-\delta}, \\
& B(\bar{m})=\left\{\frac{\beta\left(1+l_{\theta} m\right)^{\beta-1}\left[1-l_{\theta}\right]}{N \gamma_{\theta}}\right\}^{\frac{\beta}{2-\beta}} \times \frac{\beta}{N(2-\beta)}\left\{(1-\beta)\left(1+l_{\theta} m\right)^{\beta-2} l_{\theta}\left[1-l_{\theta}\right]\right\},
\end{aligned}
$$


Table 1 Firm's profits maximising degree

\begin{tabular}{llllllllll}
\hline$\delta$ & $\varepsilon=0$ & $\varepsilon=0.005$ & $\varepsilon=0.05$ & $\varepsilon=1$ & $\varepsilon>1$ & $\varepsilon=0.05$ & $\varepsilon=0.05$ & $\varepsilon=0.05$ & $\varepsilon=0.05$ \\
& $N=20$ & $N=20$ & $N=20$ & $N=20$ & $N=20$ & $N=10$ & $N=50$ & $N=10^{2}$ & $N=10^{3}$ \\
\hline 0 & - & $17_{[2]}$ & $17_{[2]}$ & $17_{[2]}$ & $17_{[2]}$ & $7_{[2]}$ & $47_{[2]}$ & $9_{[2]}$ & $9_{[2]}$ \\
0.01 & $0_{[0]}$ & $\mathbf{0}_{[2]}$ & $17_{[2]}$ & $17_{[2]}$ & $17_{[2]}$ & $7_{[2]}$ & $\mathbf{3 1}_{[2]}$ & $\mathbf{4 2}_{[2]}$ & $\mathbf{9 8}_{[2]}$ \\
0.1 & $0_{[0]}$ & $\mathbf{0}_{[1]}$ & $\mathbf{3}_{[2]}$ & $17_{[2]}$ & $17_{[2]}$ & $\mathbf{2}_{[2]}$ & $\mathbf{6}_{[2]}$ & $\mathbf{9}_{[2]}$ & $\mathbf{2}_{[2]}$ \\
0.3 & $0_{[0]}$ & $0_{[0]}$ & $\mathbf{2}_{[2]}$ & $17_{[2]}$ & $17_{[2]}$ & $\mathbf{0}_{[2]}$ & $\mathbf{5}_{[2]}$ & $\mathbf{8}_{[2]}$ & $\mathbf{2 5}_{[2]}$ \\
0.5 & $0_{[0]}$ & $0_{[0]}$ & $\mathbf{4}_{[2]}$ & $17_{[2]}$ & $17_{[2]}$ & $\mathbf{2}_{[2]}$ & $\mathbf{1 0}_{[2]}$ & $\mathbf{1 6}_{[2]}$ & $\mathbf{5 8}_{[2]}$ \\
0.7 & $0_{[0]}$ & $0_{[0]}$ & $17_{[2]}$ & $17_{[2]}$ & $17_{[2]}$ & $7_{[2]}$ & $47_{[2]}$ & $\mathbf{8 2}_{[2]}$ & $\mathbf{3 6 2}_{[2]}$ \\
0.9 & $0_{[0]}$ & $\mathbf{1 6}_{[2]}$ & $17_{[2]}$ & $17_{[2]}$ & $17_{[2]}$ & $7_{[2]}$ & $47_{[2]}$ & $9_{[2]}$ & $9_{[2]}$ \\
0.99 & $0_{[0]}$ & $17_{[2]}$ & $17_{[2]}$ & $17_{[2]}$ & $17_{[2]}$ & $7_{[2]}$ & $47_{[2]}$ & $9_{[2]}$ & $997_{[2]}$ \\
1 & - & $17_{[2]}$ & $17_{[2]}$ & $17_{[2]}$ & $17_{[2]}$ & $7_{[2]}$ & $47_{[2]}$ & $9_{[2]}$ & $997_{[2]}$ \\
\hline
\end{tabular}

Partially connected networks are in bold

Parametrization: $\beta=0.5 ; \tau=10^{4} ; r=10^{6} ; l_{\theta}=l_{x}=0.5 ; \gamma_{\theta}=\gamma_{x}=10^{3} ; \mathrm{c}=0$

where $m=\bar{m}+2$. If the ratio $\left[\frac{A(\bar{m})}{B(\bar{m})}\right]^{\frac{2-\beta}{2}}$ is increasing with $\bar{m}$ then, for a sufficiently low level of $\varepsilon \neq 0$, there exists $0<\tilde{m}<N-3$ such that $\tilde{m}=\operatorname{argmax} \pi^{*}$.

Proof See Appendix.

Obviously, we can follow the same procedure to find conditions under which the intermediate level $s=1$ maximises each firm's profits. Assuming $\frac{\partial \pi^{*}}{\partial \bar{m}}<0 \forall \bar{m}, s$ so that $\bar{m}=0$, and treating $s$ as a continuum variable into the domain $[0,2]$, we can have the case with $\frac{\partial \pi^{*}}{\partial s}<0$ if $s<\tilde{s}$ and $\frac{\partial \pi^{*}}{\partial s} \geq 0$ if $s \geq \tilde{s}$ from which we get $\tilde{s}=$ $\operatorname{argmax} \pi^{*}$. If $\tilde{s}$ is sufficiently close to 1 , then we can conclude that the network $0_{[1]}$ maximises firms' profits.

In Table 1 we report the results from numeric simulations for firm's profit maximising degree under alternative combinations of parameters $\delta, \varepsilon$ and $N$. We have emphasized partially connected networks, where $\bar{m}<N-3$ or $s=1$.

Table 1 allows us to draw the following result.

Proposition 2 Quality improving networks tend to be denser than networks aimed at sharing process innovation.

Proof First observe that quality improving networks are characterised by high $\varepsilon$ (i.e quality sharing is more relevant in forming alliances relative to process innovation). However, when $\varepsilon$ approaches to zero, product quality plays a negligible role (see condition (5)) and alliances are mainly driven by process innovation. From conditions (29) and (30) and for a sufficiently high $\varepsilon$, we obtain $\frac{\partial \pi^{*}}{\partial s}>0$ and $\frac{\partial \pi^{*}}{\partial \bar{m}}>0$. This means that when product quality is important, cooperation networks will be more dense. On the contrary, if $\varepsilon$ approaches to zero, we obtain $\frac{\partial \pi^{*}}{\partial s}<0, \frac{\partial \pi^{*}}{\partial \bar{m}}<0$ and 


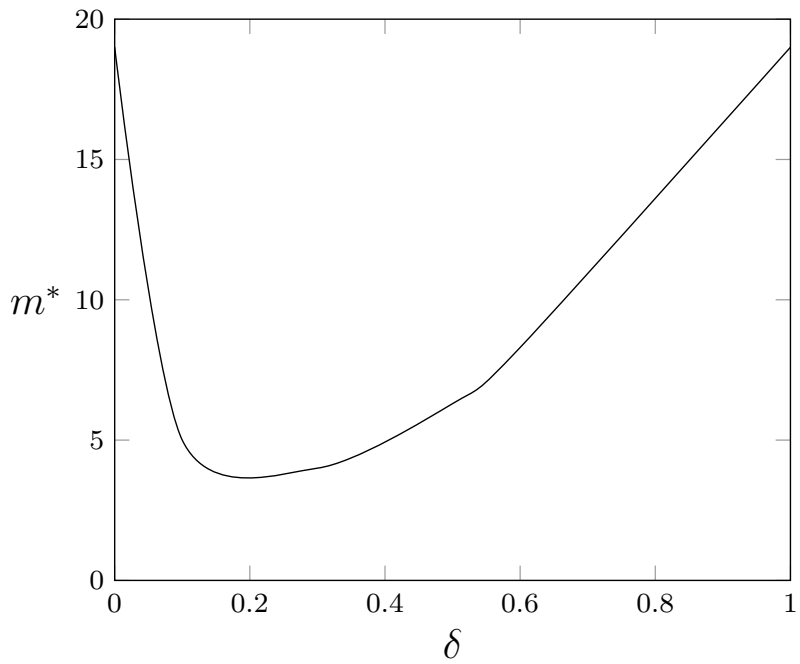

Fig. 4 The U-shaped relationship between $\delta$ and $m^{*}$, with $\varepsilon=0.05$ and $N=20$

cooperation will be driven by process innovation and characterised less dense networks.

Interestingly, we observe a U-shaped relationship between $\delta$ and the profit maximising degree $m^{*}$ (see Fig. 4).

To explain this fact, first note that $\delta=0$ (non-specialised R\&D investment) allows firms to absorb all the effort of their partners without increasing their own effort whereas, with $\delta \rightarrow 1$ the absorptive capacity function in (6) is set at zero. In the first case, process innovation spills over to each linked firms at zero cost. Thus, firms have more incentive to form links. However, when $\delta$ is sufficiently close to 1 , absorptive capacity plays no role in the formation of cooperative links and firms will cooperate only to share quality with the consequence that networks will be denser.

However, for an intermediate level of $\delta$ and sufficiently small but positive $\varepsilon$, we observe that firms' profits are maximised by an intermediate network degree $0 \leq \bar{m}_{[s]} \leq N-1$ because neither the negative effect of process innovation spillovers nor the positive effect of quality sharing prevail. Finally, for sufficiently small but positive $\delta$ and $\varepsilon$ we may have $\frac{\partial \pi^{*}}{\partial s}>0$ and $\frac{\partial \pi^{*}}{\partial \bar{m}}<0 \forall \bar{m}, s$ with the consequence that firms maximise profits forming links only with their neighbours, i.e. $m=0_{[2]}$.

The following Proposition aims to identify the conditions under which complete and empty networks are profit maximising.

Proposition 3 i) The complete network maximises firms' profits $\left(m^{*}=(N-3)_{[2]}=N-1\right)$ when $\delta \rightarrow 1, \delta \rightarrow 0$ or $l_{x} \rightarrow 0$. ii) On the contrary, the profits are maximised by the empty network $\left(m^{*}=0_{[0]}=0\right)$ when $l_{\theta} \rightarrow 0, \beta \rightarrow 0$ or $\varepsilon \rightarrow 0$. 
Proof According to conditions (29) and (30) it is straightforward to show that the first statement of Proposition 3 is confirmed by $\lim _{\delta \rightarrow 0} \frac{\partial \pi^{*}}{\partial s} \geqslant 0, \lim _{\delta \rightarrow 1} \frac{\partial \pi^{*}}{\partial s} \geqslant 0$, $\lim _{l_{x} \rightarrow 0} \frac{\partial \pi^{*}}{\partial s} \geqslant 0 \forall \bar{m}, s$ and $\lim _{\delta \rightarrow 0} \frac{\partial \pi^{*}}{\partial \bar{m}} \geqslant 0, \lim _{\delta \rightarrow 1} \frac{\partial \pi^{*}}{\partial \bar{m}} \geqslant 0, \lim _{l_{x} \rightarrow 0} \frac{\partial \pi^{*}}{\partial \bar{m}} \geqslant 0 \forall \bar{m}, s$. Likewise, the second statement stems from $\lim _{\beta \rightarrow 0} \frac{\partial \pi^{*}}{\partial s}<0, \lim _{\beta \rightarrow 0} \frac{\partial \pi^{*}}{\partial \bar{m}}<0$ $\forall \bar{m}, s$ and $\lim _{l_{\theta} \rightarrow 0} \frac{\partial \pi^{*}}{\partial \bar{m}}<0, \lim _{l_{\theta} \rightarrow 0} \frac{\partial \pi^{*}}{\partial s}<0 \quad \forall \bar{m}, s$. Finally, $\lim _{\varepsilon \rightarrow 0} \frac{\partial \pi^{*}}{\partial \bar{m}}<0$ and $\lim _{\varepsilon \rightarrow 0} \frac{\partial \pi^{*}}{\partial s}<0 \forall \bar{m}, s$.

The conditions in $i$ ) entail a fixed level of process $R \& D$ effort $x^{*}=\frac{1}{\gamma N}$ because either absorptive capacity is null $\left(l_{\theta}=0, \delta=1\right)$ or the investment $x$ does not affect firm's ability to absorb technology from its partners $(\delta=0)$. In this case, link formation only affects firm profits through product $\mathrm{R} \& \mathrm{D}$ investment $\theta$. Given a positive rate of spillover, $l_{\theta}>0$, each firm increases its profits by both lowering its own quality investment and increasing the number of cooperative links to absorb the quality effort of the other firms.

Turning to point $i i)$, when there are no quality spillovers $\left(l_{\theta}=0\right)$, each firm's product R\&D investment becomes $\theta^{*}=\left(\frac{\varepsilon \beta}{\gamma_{\theta} N}\right)^{\frac{1}{2-\beta}}$ and link formation will affect profits only through process R\&D investment. From condition (14) we know that firm's profits are decreasing with the investment $x$ which, in turn, is increasing with the network degree $m$. Thus, firms maximise their profits remaining isolated, i.e. forming an empty network.

Likewise, if product quality does not affect consumer's demand $(\beta=0, \varepsilon=0)$ firms do not invest in product innovation and $\theta^{*}=0$. Also in this case, firms might prefer to remain isolated because higher network degree implies higher cost of process innovation and thus lower profits (see the first column in Table 1).

\subsection{Welfare analysis}

In this Section we investigate the welfare implications of network formation. Specifically, we construct a welfare measure as the sum of consumer utility and firm profit; in this case consumer utility coincides with the standard measure of consumers surplus. Although elementary, this measure can be used to address some of the issues which arise naturally in the debate about the most appropriate policy to follow in regulating $\mathrm{R} \& \mathrm{D}$ cooperation between firms.

More formally, social welfare from a network (graph) $g$ can be defined as follows:

$$
W(g)=N \pi^{*}+C S,
$$

where $C S=\int_{0}^{1} u(z) d z=\left(r^{*}(m)-p^{*}(m)\right)+r-\tau \int_{0}^{1}\left|l_{k}-z\right| d z$ denotes consumer surplus, with $r^{*}(m)=\varepsilon\left[\theta^{*}\left(1+l_{\theta} m\right)\right]^{\beta}$.

With this tool at hand we can ask the following question: given that the public authority can impose the nature of the coordination agreement, namely quality improving or process-innovation based alliances, is it always preferable to allow such coordination to continue? This case may arise, for example, when the public authority is able to force or induce firms making a discovery to license it to their competitors, even in the absence of any agreement to do so. 
We examine the welfare ranking in the following Proposition 4, in which we specifically address how process and quality spillovers affect welfare. Proposition 5 seeks out if product and process innovation may give rise to a general trend to overor under-connected links. This is a way to assess how the degree of competition in the product market may affect the incentive to cooperate and/or to invest in the cooperative agreement. Propositions 4 and 5 both make use of Lemma 3 which is just an intermediate step to draw the key results.

Formally, let us define with $m_{W}^{*}, m_{C S}^{*}$ and $m_{\pi}^{*}$ respectively the welfare, consumer surplus and profits maximising degrees. As before, for each $m^{*}$ we distinguish neighbour firms from the other firms (i.e. $m^{*}=\bar{m}_{[s]}=\bar{m}+s$ ). A first important result is stated in the following Lemma:

Lemma 3 The complete network maximises consumer surplus, i.e. $m_{C S}^{*}=(N-3)_{[2]}$, if $l_{\theta} \leq \frac{1}{N+1}$.

Proof Differentiating the consumer surplus with respect to $\bar{m}$ and $s$ we obtain $\frac{\partial C S}{\partial \bar{m}}=\frac{\partial r^{*}(m)}{\partial \bar{m}}-\frac{\partial p^{*}(m)}{\partial \bar{m}}$ and $\frac{\partial C S}{\partial s}=\frac{\partial r^{*}(m)}{\partial s}-\frac{\partial p^{*}(m)}{\partial s}$.

From Eq. (11) it is straightforward to show that $\frac{\partial p^{*}(m)}{\partial \bar{m}} \leq 0$ and $\frac{\partial p^{*}(m)}{\partial s} \leq 0 \forall \bar{m}, s$ whereas

$$
\frac{\partial r^{*}(m)}{\partial \bar{m}}=\varepsilon \beta\left[\theta^{*}\left(1+l_{\theta} m\right)\right]^{\beta-1}\left[\frac{\partial \theta^{*}}{\partial \bar{m}}\left(1+l_{\theta} m\right)+\theta^{*} l_{\theta}\right]
$$
and $\frac{\partial r^{*}(m)}{\partial s}=\varepsilon \beta\left[\theta^{*}\left(1+l_{\theta} m\right)\right]^{\beta-1} \times\left[\frac{\partial \theta^{*}}{\partial s}\left(1+l_{\theta} m\right)+\theta^{*} l_{\theta}\right]$ are positive only if, respectively, $\frac{\partial \theta^{*}}{\partial \bar{m}}\left(1+l_{\theta} m\right)+\theta^{*} l_{\theta} \geq 0$ and $\frac{\partial \theta^{*}}{\partial s}\left(1+l_{\theta} m\right)+\theta^{*} l_{\theta} \geq 0 \forall \bar{m}, s$, where $\frac{\partial \theta^{*}}{\partial \bar{m}} \leq 0$ and $\frac{\partial \theta^{*}}{\partial s} \leq 0$ by Proposition 1. Firstly, $\frac{\partial \theta^{*}}{\partial \bar{m}}\left(1+l_{\theta} m\right)+\theta^{*} l_{\theta} \geq 0$ boils down to $\frac{1-\beta}{2-\beta} \leq 1$ which holds for every $0 \leq \beta \leq 1$. Secondly, by calculation, we obtain that $\frac{\partial \theta^{*}}{\partial s}\left(1+l_{\theta} m\right)+\theta^{*} l_{\theta} \geq 0$ if $l_{\theta} \leq \frac{1}{\bar{m}+2 s}$. Given that the smallest value of $\frac{1}{\bar{m}+2 s}$ is $\frac{1}{N+1}$, we can write the sufficient condition $l_{\theta} \leq \frac{1}{N+1}$.

According to Lemma 3, link formation with neighbouring firms increases $C S$ if quality spillovers are sufficiently low. The economic intuition behind this result is that when $l_{\theta}$ is sufficiently small, firms can increase their own quality level $\theta$ and form cooperative agreements without running the risk of increasing the quality of the neighbouring firms and reducing their market demand. In other words, increasing $m^{*}$ lowers product quality, but this effect is mitigated by a small spillover rate $l_{\theta}$ which, in turn, encourages firms to increase product quality (see condition (12)) and thus consumer surplus.

We are now able to identify sufficient conditions under which total welfare is maximised by the complete network. We summarise this result in the following Proposition.

Proposition 4 If $\delta \rightarrow 1, \delta \rightarrow 0$ or $l_{x} \rightarrow 0$ and $l_{\theta} \leq \frac{1}{N+1}$ then the complete network maximises social welfare, i.e. $m_{W}^{*}=(N-3)_{[2]}$.

Proof According to Proposition 3, when $\delta \rightarrow 1, \delta \rightarrow 0$ or $l_{x} \rightarrow 0$ the complete network maximises firms' profits, i.e $m_{\pi}^{*}=(N-3)_{[2]}$. On the other hand, by Lemma 3 
Table 2 Welfare maximising degree

\begin{tabular}{llllllllll}
\hline$l_{\theta}$ & $\delta=0$ & $\delta=0.1$ & $\delta=0.5$ & $\delta=0.7$ & $\delta=1$ & $\delta=0$ & $\delta=0$ & $\delta=0$ & $\delta=0$ \\
& $N=20$ & $N=20$ & $N=20$ & $N=20$ & $N=20$ & $N=4$ & $N=10$ & $N=10^{2}$ & $N=10^{3}$ \\
\hline 0 & $\mathbf{1 7}_{[2]}$ & $\mathbf{1 7}_{[2]}$ & $\mathbf{1 7}_{[2]}$ & $\mathbf{1 7}_{[2]}$ & $\mathbf{1 7}_{[2]}$ & $\mathbf{1}_{[2]}$ & $\mathbf{7}_{[2]}$ & $\mathbf{9 7}_{[2]}$ & $\mathbf{9 9 7}_{[2]}$ \\
0.01 & $\mathbf{1 7}_{[2]}$ & $\mathbf{1 7}_{[2]}$ & $\mathbf{1 7}_{[2]}$ & $\mathbf{1 7}_{[2]}$ & $\mathbf{1 7}_{[2]}$ & $\mathbf{1}_{[2]}$ & $\mathbf{7}_{[2]}$ & $9_{[2]}$ & $9_{[0]}$ \\
0.03 & $\mathbf{1 7}_{[2]}$ & $\mathbf{1 7}_{[2]}$ & $\mathbf{1 7}_{[2]}$ & $\mathbf{1 7}_{[2]}$ & $\mathbf{1 7}_{[2]}$ & $\mathbf{1}_{[2]}$ & $\mathbf{7}_{[2]}$ & $9_{[0]}$ & $9_{\left[07_{[0]}\right.}$ \\
0.1 & $17_{[2]}$ & $17_{[2]}$ & $17_{[2]}$ & $17_{[2]}$ & $17_{[2]}$ & $\mathbf{1}_{[2]}$ & $7_{[2]}$ & $9_{[0]}$ & $9^{997_{[0]}}$ \\
0.3 & $17_{[0]}$ & $17_{[0]}$ & $17_{[0]}$ & $17_{[0]}$ & $1_{[0]}$ & $1_{[2]}$ & $7_{[0]}$ & $97_{[0]}$ & $9_{\left[07_{[0]}\right.}$ \\
0.5 & $17_{[0]}$ & $17_{[0]}$ & $17_{[0]}$ & $17_{[0]}$ & $17_{[0]}$ & $1_{[1]}$ & $7_{[0]}$ & $97_{[0]}$ & $9_{[0]}$ \\
0.7 & $17_{[0]}$ & $17_{[0]}$ & $17_{[0]}$ & $17_{[0]}$ & $17_{[0]}$ & $1_{[1]}$ & $7_{[0]}$ & $97_{[0]}$ & $9_{[0]}$ \\
0.9 & $17_{[0]}$ & $17_{[0]}$ & $17_{[0]}$ & $17_{[0]}$ & $17_{[0]}$ & $1_{[1]}$ & $7_{[0]}$ & $97_{[0]}$ & $997_{[0]}$ \\
1 & $17_{[0]}$ & $17_{[0]}$ & $17_{[0]}$ & $17_{[0]}$ & $17_{[0]}$ & $1_{[0]}$ & $7_{[0]}$ & $97_{[0]}$ & $997_{[0]}$ \\
\hline
\end{tabular}

Networks with $l_{\theta} \leq \frac{1}{N+1}$ are in bold

Parametrization: $\beta=0.5 ; \tau=10^{4} ; r=10^{6} ; l_{x}=0.5 ; \gamma_{\theta}=\gamma_{x}=10^{3} ; \varepsilon=10^{3} ; c=0$

we know that $m_{C S}^{*}=(N-3)_{[2]}$ under the suitable condition $l_{\theta} \leq \frac{1}{N+1}$. Then, given that $W=C S+N \pi^{*}$, we conclude that $m_{W}^{*}=(N-3)_{[2]}$.

Proposition 4 states that link formation is welfare improving if both process and quality spillovers ( $l_{x}$ and $l_{\theta}$ respectively) are sufficiently small. However, when $\delta$ (the $R \& D$ approach) takes limit (extreme) values then firms profits (which account for a major part of welfare) are maximised by denser networks. Put it differently, when $\delta=1$, firm R\&D approach is too specific and they cannot receive positive spillovers from their partners because the information they provide is irrelevant to them. On the other extreme, $\delta=0$ implies a totally non-specific R\&D approach and every firm has the highest absorptive capacity for any level of its R\&D investment. It is worth noticing that this formulation excludes the possibility of manna from heaven given that firms cannot benefit from partner R\&D spillovers without engaging in process R\&D itself.

In Table 2 we report the numerical counterpart of the Proposition 4, specifically the number of connections which maximise total welfare for different combinations of $\delta, l_{\theta}$ and $N$. We have emphasized the cases in which condition $l_{\theta} \leq \frac{1}{N+1}$ is satisfied.

Let us observe that as $l_{\theta}$ converges to 1 , firms reduce their quality effort $\theta$ with the consequence that consumer surplus $C S$ and welfare $W$ decreases. However, this negative effect can be attenuated by severing links among neighbouring. Indeed, for any firm $i$, the adjacent firms $i-1$ and $i+1$ are direct competitors so they are more sensitive to variation of firm $i$ 's quality effort. This fact implies that firm $i$ can maintain higher levels of quality $\theta_{i}$ even if $l_{\theta}$ is large, if it is not linked with its own neighbouring firms $i-1$ and $i+1$ (remember that firms use links as a means to decrease their quality effort). As a consequence, for high quality spillovers, the welfare maximising network degree tends to $m^{*}=(N-3)_{[0]}$. Such a tendency is much 
more evident with a larger number of firms, because of the increasing competition among neighbouring firms.

The model is also able to draw some conclusions in relation to possible over or under connections product and process innovation. We find general tendency to under-connection with respect to social welfare when link formation is driven by process innovation; on the contrary, we observe that networks of alliances tend to be over-connected as compared to the social optimum if quality-improving alliances prevail. The result is summarised in the following Proposition.

Proposition 5 1) If $l_{\theta} \rightarrow 0$ or equivalently $l_{\theta} \leq \frac{1}{N+1}$ and $\beta \rightarrow 0$ then $m_{\pi}^{*} \leq m_{W}^{*} \leq m_{C S}^{*}$. 2) If $l_{\theta}>\frac{1}{N+1}$ and $\delta \rightarrow 1, \delta \rightarrow 0$ or $l_{x} \rightarrow 0$ then $m_{C S}^{*} \leq m_{W}^{*} \leq m_{\pi^{*}}^{*}$.

Proof 1) From point $i$ ) in Proposition 4 we know that the profits maximising degree is zero, $m_{\pi}^{*}=0_{[0]}$, if $l_{\theta} \rightarrow 0$ or $\beta \rightarrow 0$. Moreover, the assumption $l_{\theta} \leq \frac{1}{N+1}$ (which trivially holds if $\left.l_{\theta} \rightarrow 0\right)$ implies $m_{C S}^{*}=(N-3)_{[2]}$ from which we conclude that $m_{C S}^{*}>m_{\pi}^{*}$. Finally, from $W=C S+N \pi^{*}$ it is straightforward to show that $m_{\pi}^{*} \leq m_{W}^{*} \leq m_{C S}^{*}$. 2) From point $i$ ) in Proposition 4, if $\delta \rightarrow 1, \delta \rightarrow 0$ or $l_{x} \rightarrow 0$ then $m_{\pi}^{*}=(N-3)_{[2]}$. Moreover, if $l_{\theta}>\frac{1}{N+1}$ then $m_{C S}^{*}=(N-3)_{[s]}$ because $s \leq 2$ and $m_{C S}^{*} \leq m_{\pi}^{*}$. As before, given that $W=C S+N \pi^{*}$, we obtain $m_{C S}^{*} \leq m_{W}^{*} \leq m_{\pi}^{*}$ where $m_{W}^{*}=(N-3)_{[s]}$ with $s \leq 2$.

Points 1) and 2) in Proposition 5 are supported by numerical simulations as is reported in Tables 3 and 4 in the appendix (the numerical parametrization is also reported). This result stems from the fact that process innovation enhances firm's ability to learn from partners making it more competitive (positive externalities ). As a result, firms are induced to reduce both connections and their own effort with the aim to restrict competition and increase profits. Differently, with product innovation networks there is a high risk of free riding, that is firms can increase their own product quality without investing in quality (negative externalities). Therefore, firms will tend to reduce their quality effort and to increase the number of cooperative links, giving rise to over-connected networks. Proposition 4 thus states that promoting $R \& D$ cooperation among firms can be a welfare improving policy if spillovers are sufficiently small. This is an important theoretical contribution to the literature concerning the role of public intervention in R\&D networks. Many studies have examined the effectiveness of subsides and public programmes to sustain firms' cooperation. Leahy and Neary (1997), for example, study the relationship between subsidies and social welfare showing that cooperation among firms is independent of the subsidies received from the government. Consequently, R\&D networks should not be subsidized. On the contrary, Yi and Shin (2000) prove that promoting $\mathrm{R} \& \mathrm{D}$ subsidies is always welfare improving and leads to the formation of denser networks which represents the socially optimal best solution. These conflicting results can be read as showing the difficulty of evaluating public R\&D programmes (see also Falk 2007; Lukkonen 1998) and it is likely to suggest that the cause-effect relationship between public policy and private $\mathrm{R} \& \mathrm{D}$ cooperation is not as straightforward as policy-makers often suppose. Based on these considerations, results 
stated in Propositions 4 allow us to make a step forward in the debate, providing an additional criterion to evaluate the appropriateness of public programmes aimed at increasing firm R\&D cooperation and social welfare. Whereas consumers and social costs move in the same direction, firms perceive differently the main outcome of the collaboration activity, given the precence of R\&D spillovers: positive for society and bad for firms. The policy implication we can learn from the results is that promoting R\&D agreements among firms, in a context characterised by both product and process innovation, is welfare improving only when the market displays sufficiently low level of spillovers. However, as reported in 1) of Proposition 5, low spillovers may give rise to under-connected networks. Then, it could be profitable to stimulate the formation of $R \& D$ partnership by providing more lenient anti-trust rules even if this policy route needs to be treated with caution given that firms may use R\&D cooperation to make their collusive agreements more stable (Martin 1995).

Proposition 5 describes the tension between private profits and efficiency. In contrast to Buechel and Hellmann (2012) findings, the prevalence of negative externalities $\left(l_{\theta} \rightarrow 0\right.$ and $l_{x}>0$; point 1 of Proposition 5) leads to situations where firms are not willing to form links, although it would be beneficial from the welfare point of view. In other words, networks tend to be under-connected. On the contrary, the predominance of positive externalities $\left(l_{x} \rightarrow 0\right.$ and $l_{\theta}>0$; point 2 of Proposition 5) entail over-connected networks.

\section{Discussion}

In this section we discuss the main results of the model, providing the relevant policy implications. The key result of the paper is that quality networks tend to be denser and over-connected. In this case, firms reduce their own effort and increase cooperative links. Hence, from the foregoing discussion we can conclude that firms prefer to form quality-improving networks than those characterized by process innovation sharing provided that spillovers do not eliminate the benefit of making profits from alliances. Put it different, cooperating firms are inclined to set a lower product quality to limit partner advantages at their expenses. This effect, however, is mitigated by a lower spillover rate, which reduces the tendency of opportunistic behaviours from firms. The opposite is true in presence of process innovation, where high spillovers may generate higher incentive for collaboration.

To be sure, cooperation in R\&D may mitigate the costly effects of effort duplication for innovation activities by internalizing the externalities created by spillovers. Nonetheless, cooperation lowers the costs not only for each firm but also for the associated competitors, making them less incline to linking and thus penalizing cooperation in R\&D.

This result relies on an important and implicit feature of the R\&D activity, that is the possibility of giving and receiving spillovers: R\&D investment may have positive effects on another firm innovation activity and vice-versa. The more recent literature has pointed out how spillovers may affect adversely the incentive to invest in $R \& D$ : the fact that $R \& D$ investments will help some competitors will generally weaken the incentive to invest. Hence, being aware that $R \& D$ investments might 
help product market competitors will generally weaken the incentive to invest. d'Aspremont and Jacquemin (1988) discuss how cooperative R\&D agreements between otherwise competing firms may help firms internalise these externalities, resulting in improvements in the level of social welfare. This work is extended to the case of more than two firms and more general assumptions by Suzumura (1992) and by Motta (1992). We also analyse how process and quality spillovers affect welfare. The most interesting conclusion we reach is that the best choice from a social welfare point of view is to incentive quality and process collaborations provided that spillovers are sufficiently small. It is thus possible that, even in this static framework with low spillovers, a fully collaborative setting is the best possible option, even when more competitive arrangements could be imposed by the public authority. In this respect, our analysis suggests some interesting policy conclusions relative to the attitude towards collusion among firms. Policies aimed at stimulating strategic alliances should take into account (and/or take advantage of) the implicit trade-off arising from the presence of product, process innovation and spillovers. Hence, policy-makers should implement, on the one hand, policies leading to enhance process innovation networks; on the other hand, it may promote policies for product quality but limiting in a way opportunistic behaviours. In this sense, this result would suggest that, at least in the case of the spillovers considered in this paper, policy makers should not try to draw rigid rules for the treatment of any proposed collaboration, and that a case by case approach is called for. In this context proper analysis of the incentives to cooperate in R\&D should be based on a detailed understanding of the circumstances in which cooperation occurs, with a specific focus on spillovers.

\section{Some variants of the model}

This Section introduces some variants of the model. This analysis may be very useful to check the robustness of the previous results against changes in some hypotheses that might be particularly relevant in driving the results. Technical details are reported in the appendix.

In the basic version of the model we have assumed that when two firms form a link, they share both product and process innovation at the same time. A further step of the analysis is to assume two types of links. A link to share quality (Q-link) and a link to cooperate in process innovation (P-link). In this respect let us indicate with $m_{\theta}=\bar{m}_{\theta}+s_{\theta}$ and $m_{x}=\bar{m}_{x}+s_{x}$ the number of links formed to share, respectively, quality efforts and process innovation. From removing the assumption of complementarity between quality and process innovation, we allow firms to form two independent networks. We find that networks based on quality sharing will be denser because firms tend to increase links and free ride on investment made by their partners. Differently, process innovation networks are only driven by absorptive capacity. In this case firms are better off by increasing their own investment $x$ and remaining isolated. In the Appendix we report the technical details and show that the profit maximising degrees are $m_{\theta}=N-1$ and $m_{x}=0$, whereas social welfare is measured by the complete network. We summarise these results in Propositions 7 and 8 . 
We also explore the implications of a general consumer distribution on network formation, showing how the previous results (as in the Paragraph 3) may change under this hypothesis. Specifically, we assume that consumers are distributed along the Salop's circle with a continuous, differentiable and positive density $f(z)$. We confirm the results of the benchmark model but observe that the level of prices changes. Precisely, firms increase prices but not the optimal R\&D effort. Hence, the effect of link formation on profits and social welfare does not change.

We also formulate a different hypothesis about prices. In the basic version of the model we have assumed that firms are able to set their price in the second stage of the game according to their production costs. In this case we remove this hypothesis by assuming a constant level of price across firms. We thus can assume that firms charge the same exogenous price $\hat{p}$ for the product and choose R\&D efforts $\theta_{i}$ and $x_{i}$ at the second stage. We find that the complete network maximises both firms' profits and welfare (technical details in the Appendix). Some examples of this case concern health care and high education (Correani and Di Dio (2019), Brekke et al. (2006)). ${ }^{5}$

\section{Conclusion}

We study quality improving and process innovation alliances in an oligopolistic context à la Salop. We find that the quality effort decreases with cooperation because firms prefer to have a lower product quality rather than make the partners better at their expense. However, given the assumption of absorptive capacity, R\&D process investment increases with cooperation. This result depends on the fact that firms have incentive to increase their effort as the number of partners increases. We also show that quality-improving networks tend to be denser than networks characterized by process innovation sharing. This is why when quality alliances prevail, firms maximise profits by reducing their own effort on product quality and increasing the number of partners. Finally, we find that link formation is welfare improving if both absorptive capacity and quality spillovers are sufficiently small. Also we detect the key drivers that push firms to under-(over-) connecting when link formation is channelled by process innovation (product innovation). More precisely, cooperation is affected by opportunistic behaviours (free-riding), which induce firms to form over-connected networks, and by absorptive capacity which reduces the incentive to cooperate, giving rise to under-connected networks. Which effect will prevail depends on the main parameters of the model such as the rate of spillover, the technological approach of firms and the elasticity of the quality index. In addition we introduce some variants of the model to check how the model results change after

\footnotetext{
5 Correani and Di Dio (2019) study stability and efficiency of R\&D collaboration in a threee firm Hotelling game with fixed price whereas Brekke et al. (2006) analyse the equilibrium outcomes in a model of spatial competition à la Hotelling where the product price is exogenous and firms compete on quality. By assuming fixed price, we try to bring together these two approaches to analyse network formation in a symmetric differentiated oligopoly (Salop) where firms provide public services and the price is set by a regulator. Generally, in both these sectors price is set by some regulatory authority and firms will resort to strategic vertical and horizontal differentiation to attract consumers.
} 
the modifications of some key hypotheses. In particular we extend the analysis of link formation to the case of heterogeneous links, where firms could share quality or process innovation links; the case of non-uniform consumer distribution and the case in which prices are constant are also covered. Moreover, the main conclusions of the paper can be interpreted as stressing that, when R\&D is involved, all is possible, and no clear-cut rules should be applied: to reach this conclusion, a specific example is needed.

Nevertheless, the model is based deliberately on a number of simplifying assumptions in order to highlight the intuition behind the results. However, the analysis may be both of pedagogical value and be fruitfully used in managerial and industrial organization analysis.

We believe that the model we present in this paper can be extended along several dimensions. At least two future research lines can be pursued. Firstly, we could consider strategic firm location implying endogenous distribution of firms, to study whether cooperation links induce firms to agglomerate or differentiate. Secondly, a natural question is to what extent our approach extends to alternative spatial models, such as the spoke model and the Hotelling model. In this latter case, our results might change due to the asymmetries between corner and internal firms.

Open Access This article is licensed under a Creative Commons Attribution 4.0 International License, which permits use, sharing, adaptation, distribution and reproduction in any medium or format, as long as you give appropriate credit to the original author(s) and the source, provide a link to the Creative Commons licence, and indicate if changes were made. The images or other third party material in this article are included in the article's Creative Commons licence, unless indicated otherwise in a credit line to the material. If material is not included in the article's Creative Commons licence and your intended use is not permitted by statutory regulation or exceeds the permitted use, you will need to obtain permission directly from the copyright holder. To view a copy of this licence, visit http://creativecommons.org/licen ses/by/4.0/.

\section{Appendix}

\section{Proof of Claim 1 Positivity}

From condition (14) we know that $\pi^{*}>0$ if $\frac{\tau}{N^{2}}>\left[\frac{\gamma_{x}}{2}\left(x^{*}\right)^{2}\right]+\left[\frac{\gamma_{\theta}}{2}\left(\theta^{*}\right)^{2}\right]$. The two terms on the right hand side have, respectively, an upper limit of $\frac{1}{2 \gamma_{x}}$ and $\frac{\varepsilon^{2}}{2 \gamma_{\theta} N^{2}}$. This allows us to establish that firm's profits are positive if $\tau>\tau_{1} \equiv \frac{N^{2}}{2 \gamma_{x}}+\frac{\varepsilon^{2}}{2 \gamma_{\theta}}>0$.

\section{Concavity-Second order conditions}

With regard to the second order conditions, differentiating twice the profit function with respect to $p_{i}, \theta_{i}$ and $x_{i}$, then focusing on the symmetric case, we obtain the Hessian matrix $H$. By standard calculus we know that firm's profit $\pi$ reaches a local maximum at $\left(p^{*}, \theta^{*}, x^{*}\right)$ if $\nabla \pi\left(p^{*}, \theta^{*}, x^{*}\right)=0$ and $(-1)^{n} H_{n}\left(p^{*}, \theta^{*}, x^{*}\right)>0$ $n=1, \ldots, N$, where $\nabla \pi$ and $H_{n}$ are, respectively, the gradient of $\pi$ and the n-th principal minors of the Hessian matrix $H$ evaluated at $\left(p^{*}, \theta^{*}, x^{*}\right)$.

The Hessian matrix is 


$$
H\left(p^{*}, \theta^{*}, x^{*}\right)=\left(\begin{array}{lll}
\pi_{p p} & \pi_{p \theta} & \pi_{p x} \\
\pi_{\theta p} & \pi_{\theta \theta} & \pi_{\theta x} \\
\pi_{x p} & \pi_{x \theta} & \pi_{x x}
\end{array}\right)
$$

where

$$
\begin{gathered}
\pi_{p p}=-\frac{2}{\tau} ; \\
\pi_{p \theta}=\pi_{\theta p}=-\frac{(\varepsilon \beta)^{\frac{1}{2-\beta}}}{\tau\left(\gamma_{\theta} N\right)^{\frac{\beta-1}{2-\beta}}}\left(1+l_{\theta} m\right)^{\frac{\beta-1}{2-\beta}}\left[1-\frac{l_{\theta}}{2} s\right]^{\frac{1}{2-\beta}} ; \\
\pi_{p x}=\pi_{x p}=-\frac{1}{\tau}\left[1+(1-\delta) \delta l_{x} m^{1-\delta}\right] ; \\
\pi_{\theta \theta}=-(1-\beta)\left[1-\frac{l_{\theta}^{2}}{2} s\right]\left\{\frac{\gamma_{\theta}}{\left(1+l_{\theta} m\right)\left[1-\frac{l_{\theta}}{2} s\right]} \pi^{\frac{1}{\tau}\left[1+(1-\delta) \delta l_{x} m^{1-\delta}\right]\left\{\left[1-\frac{l_{\theta}}{2} s\right] \varepsilon \beta\right.}\right\}^{\frac{1}{2-\beta}}\left[\frac{1+l_{\theta} m}{\gamma_{\theta} N}\right]^{\frac{\beta-1}{2-\beta}} ; \\
\pi_{x x}=\frac{1}{N}\left\{\frac{(1-\delta) \delta(\delta-1) l_{x} m^{1-\delta}}{\frac{1}{\gamma_{x} N}\left[1+(1-\delta) \delta l_{x} m^{1-\delta}\right]}\right\}^{-\gamma_{x} .}
\end{gathered}
$$

Firstly, observe that the necessary condition for concavity always holds: $\pi_{p p} \leq 0$, $\pi_{\theta \theta} \leq 0$ and $\pi_{x x} \leq 0$.

Secondly, to check sufficient conditions for concavity we calculate the principal minors of the Hessian matrix:

$$
\begin{gathered}
H_{1}=\pi_{p p}<0 \quad \forall \tau>0 \\
H_{2}=\pi_{p p} \pi_{\theta \theta}-\pi_{p \theta}^{2}>0 \quad \text { if } \quad \tau>\tau_{2} \equiv \frac{\tilde{\pi}_{p \theta}^{2}}{-2 \pi_{\theta \theta}}>0
\end{gathered}
$$

where $\tilde{\pi}_{p \theta}=\tau \pi_{p \theta}$;

$$
H_{3}=-2 \tau^{2} \pi_{\theta \theta} \pi_{x x}-\tau\left(\tilde{\pi}_{p x}^{2} \pi_{\theta \theta}+\tilde{\pi}_{p \theta}^{2} \pi_{x x}\right)+2\left(\tilde{\pi}_{p \theta}^{2} \tilde{\pi}_{\theta x} \tilde{\pi}_{x p}+\tilde{\pi}_{\theta x}^{2}\right)<0
$$

if $\tau>\tau_{3} \equiv \frac{-B-\sqrt{B^{2}-4 A C}}{2 A}>0$ with 


$$
\begin{gathered}
A=-2 \pi_{\theta \theta} \pi_{x x}<0, \\
B=-\tilde{\pi}_{p x}^{2} \pi_{\theta \theta}-\tilde{\pi}_{p \theta}^{2} \pi_{x x}>0, \\
C=2\left(\tilde{\pi}_{p \theta} \tilde{\pi}_{\theta x} \tilde{\pi}_{x p}+\tilde{\pi}_{\theta x}^{2}\right)>0 .
\end{gathered}
$$

We conclude that the principal minors of the Hessian matrix $H$ alternate in sign, beginning with negative, if the transportation cost is sufficiently high. Summarizing, we can state that profits are positive and concave with a maximum in $\left(p^{*}, \theta^{*}, x^{*}\right)$ if $\tau>\max \left[\tau_{1}, \tau_{2}, \tau_{3}\right]$. Numerical simulations show that, under suitable values of parameters, this condition holds.

Proof of Lemma 1: Differentiating expression (14) with respect to $s$ and $\bar{m}$ we obtain:

$$
\begin{aligned}
\frac{\partial \pi^{*}}{\partial s}= & -\frac{1+(1-\delta) \delta l_{x} m^{1-\delta}}{\gamma_{x} N^{2}}(1-\delta)^{2} \delta l_{x} m^{-\delta}+ \\
- & \frac{1}{2-\beta}\left\{\frac{\varepsilon \beta\left(1+l_{\theta} m\right)^{\beta-1}}{\gamma_{\theta} N}\left[1-\frac{l_{\theta}}{2} s\right]\right\}^{\frac{\beta}{2-\beta}} \\
\times & \frac{\varepsilon \beta}{N}\left\{(\beta-1)\left(1+l_{\theta} m\right)^{\beta-2} l_{\theta}\left[1-\frac{l_{\theta}}{2} s\right]-\frac{l_{\theta}}{2}\left(1+l_{\theta} m\right)^{\beta-1}\right\}, \\
\frac{\partial \pi^{*}}{\partial \bar{m}}= & -\frac{1+(1-\delta) \delta l_{x} m^{1-\delta}}{\gamma_{x} N^{2}}(1-\delta)^{2} \delta l_{x} m^{-\delta}+ \\
& -\frac{1}{2-\beta}\left\{\frac{\varepsilon \beta\left(1+l_{\theta} m\right)^{\beta-1}}{\gamma_{\theta} N}\left[1-\frac{l_{\theta}}{2} s\right]\right\} \\
& \times \frac{\varepsilon \beta}{N}\left\{(\beta-1)\left(1+l_{\theta} m\right)^{\beta-2} l_{\theta}\left[1-\frac{l_{\theta}}{2} s\right]\right\} .
\end{aligned}
$$

Since $\frac{l_{\theta}}{2}\left(1+l_{\theta} m\right)^{\beta-1} \geq 0$ for all $m \in[0, N-1]$, it is easy to see that $\frac{\partial \pi^{*}}{\partial s} \geq \frac{\partial \pi^{*}}{\partial \bar{m}}$. As a consequence, if $\frac{\partial \pi^{*}}{\partial \bar{m}} \geq 0 \forall \bar{m}, s$, it must be $\frac{\partial \pi^{*}}{\partial s} \geq 0 \forall \bar{m}, s$; in this case firms' profits are maximised with the complete network. Differently, if $\frac{\partial \pi^{*}}{\partial \bar{m}}<0 \forall \bar{m}, s$ we can have either $\frac{\partial \pi^{*}}{\partial s}<0$ or $\frac{\partial \pi^{*}}{\partial s} \geq 0 \forall \bar{m}, s$. In the first case, firms have higher profits forming an empty network whereas, in the second one, firms maximize profits forming links with their two neighbours.

Proof of Lemma 2: We develop the proof in three points:

1. Rewrite condition (30) as $\frac{\partial \pi^{*}}{\partial \bar{m}}=-A(\bar{m})+\varepsilon^{\frac{2}{2-\beta}} B(\bar{m})$ where $A(\bar{m})>0, B(\bar{m})>0$, $\frac{\partial B(\bar{m})}{\partial \bar{m}}>0 \forall \bar{m}$.

2. From point (1) we obtain that $\frac{\partial \pi^{*}}{\partial \bar{m}} \geq 0$ if $\varepsilon \geq\left[\frac{A(\bar{m})}{B(\bar{m})}\right]^{\frac{2-\beta}{2}}$ and $\frac{\partial \pi^{*}}{\partial \bar{m}}<0$ if $\varepsilon<\left[\frac{A(\bar{m})}{B(\bar{m})}\right]^{\frac{2-\beta}{2}}$. 
3. Given point (2), if the ratio $\left[\frac{A(\bar{m})}{B(\bar{m})}\right]^{\frac{2-\beta}{2}}$ is increasing with $\bar{m}$ then, for a sufficiently low level of $\varepsilon \neq 0$ we might have $\left[\frac{A(0)}{B(0)}\right]^{\frac{2-\beta}{2}}<\varepsilon<\left[\frac{A(N-3)}{B(N-3)}\right]^{\frac{2-\beta}{2}}$ and find an intermediate value $0<\tilde{m}<N-3$ which maximises firm's profits.

\section{Variants of the model}

\section{Heterogeneous links}

Rewriting the profit function as

$$
\begin{aligned}
\pi^{*}= & \frac{\tau}{N^{2}}-\frac{\gamma_{x}}{2}\left\{\frac{1}{\gamma_{x} N}\left[1+(1-\delta) \delta l_{x} m_{x}^{1-\delta}\right]\right\}^{2} \\
& +-\frac{\gamma_{\theta}}{2}\left\{\frac{\varepsilon \beta}{\gamma_{\theta} N}\left(1+l_{\theta} m_{\theta}\right)^{\beta-1}\left[1-\frac{l_{\theta}}{2} s_{\theta}\right]\right\}^{\frac{2}{2-\beta}},
\end{aligned}
$$

a first result can be summarized in the following Proposition:

Proposition 6 If we distinguish between Q-link and P-link then the profits maximising degrees are $m_{\theta}=N-1$ and $m_{x}=0$.

Proof Differentiating the profit function (31) with respect to $m_{x}, \bar{m}_{\theta}$ and $s_{\theta}$ we obtain: i) $\frac{\partial \pi^{*}}{\partial m_{x}} \leq 0 \forall s_{\theta}, \bar{m}_{\theta}, m_{x}$; ii) $\frac{\partial \pi^{*}}{\partial \bar{m}_{\theta}} \geq 0 \forall s_{\theta}, \bar{m}_{\theta}, m_{x} ;$ iii) $\frac{\partial \pi^{*}}{\partial s_{\theta}} \geq 0 \forall s_{\theta}, \bar{m}_{\theta}, m_{x}$.

Total welfare in now $W(g)=N \pi^{*}\left(m_{x}, m_{\theta}\right)+r\left(m_{\theta}\right)+r-p^{*}\left(m_{x}\right)-\tau \int_{0}^{1}\left|l_{k}-z\right| d z$ from which we get the following result:

Proposition 7 If we distinguish between $Q$-link and P-link then the complete network with $m_{x}=m_{\theta}=N-1$ maximises total welfare.

Proof Let us indicate with $m_{x}^{*}$ and $m_{\theta}^{*}$ the social welfare maximising degrees. We have $\frac{\partial W}{\partial \bar{m}_{\theta}}=N \frac{\partial \pi^{*}}{\partial \bar{m}_{\theta}}+\frac{\partial r^{*}}{\partial \bar{m}_{\theta}} \geq 0 \forall s_{\theta}, m_{x}, \bar{m}_{\theta}$ and $\frac{\partial W}{\partial s_{\theta}}=N \frac{\partial \pi^{*}}{\partial s_{\theta}}+\frac{\partial r^{*}}{\partial s_{\theta}} \geq 0 \forall \bar{m}_{\theta}, m_{x}, s_{\theta}$, confirming that $m_{\theta}^{*}=(N-3)_{[2]}=N-1$. On the other hand, $\frac{\partial W}{\partial m_{x}}=N \frac{\partial \pi^{*}}{\partial m_{x}}-\frac{\partial p^{*}}{\partial m_{x}}$ whose sign is ambiguous because $\frac{\partial \pi^{*}}{\partial m_{x}} \leq 0$ and $\frac{\partial p^{*}}{\partial m_{x}} \leq 0$. However, by calculation it is straightforward to show that $N \frac{\partial \pi^{*}}{\partial m_{x}}-\frac{\partial p^{*}}{\partial m_{x}} \geq 0 \quad \forall \bar{m}_{\theta}, m_{x}, s_{\theta} \quad$ if $\delta(1-\delta)(2-\delta) l_{x} m_{x}^{1-\delta}+1 \geq 0$ which certainly holds, confirming that $m_{x}^{*}=(N-3)_{[2]}=N-1$.

\section{Non-uniform consumer distribution}




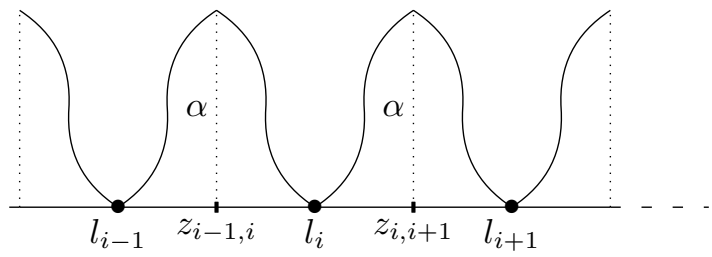

Fig. 5 Consumer distribution: high $\alpha$

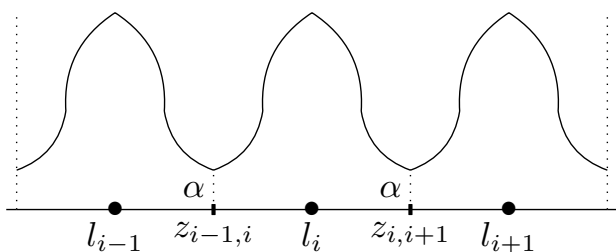

Fig. 6 Consumer distribution: low $\alpha$

Table 3 A comparison among profits, consumer surplus and welfare maximising degrees

\begin{tabular}{lllllllll}
\hline$l_{\theta}$ & & $\beta=0$ & $\beta=0.5$ & $\beta=1$ & $\beta=0$ & $\beta=0$ & $\beta=0$ & $\beta=0$ \\
& & $N=20$ & $N=20$ & $N=20$ & $N=4$ & $N=10$ & $N=10^{2}$ & $N=10^{3}$ \\
\hline 0 & $m_{\pi}^{*}$ & $\mathbf{0}_{[0]}$ & $\mathbf{0}_{[0]}$ & $\mathbf{0}_{[0]}$ & $\mathbf{0}_{[0]}$ & $\mathbf{0}_{[0]}$ & $\mathbf{0}_{[0]}$ & $\mathbf{0}_{[0]}$ \\
& $m_{C S}^{*}$ & $\mathbf{1 7}_{[2]}$ & $\mathbf{1 7}_{[2]}$ & $\mathbf{1 7}_{[2]}$ & $\mathbf{1}_{[2]}$ & $\mathbf{7}_{[2]}$ & $\mathbf{9 7}_{[2]}$ & $\mathbf{9 9 7}_{[2]}$ \\
& $m_{W}^{*}$ & $\mathbf{1 7}_{[2]}$ & $\mathbf{1 7}_{[2]}$ & $\mathbf{1 7}_{[2]}$ & $\mathbf{1}_{[2]}$ & $\mathbf{7}_{[2]}$ & $\mathbf{9 7}_{[2]}$ & $\mathbf{9 9 7}_{[2]}$ \\
0.01 & $m_{\pi}^{*}$ & $\mathbf{0}_{[0]}$ & $\mathbf{1 7}_{[2]}$ & $\mathbf{1 7}_{[2]}$ & $\mathbf{0}_{[0]}$ & $\mathbf{0}_{[0]}$ & $0_{[0]}$ & $0_{[0]}$ \\
& $m_{C S}^{*}$ & $\mathbf{1 7}_{[2]}$ & $\mathbf{1 7}_{[2]}$ & $\mathbf{1 7}_{[2]}$ & $\mathbf{1}_{[2]}$ & $\mathbf{7}_{[2]}$ & $97_{[2]}$ & $9_{[2]}$ \\
& $m_{W}^{*}$ & $\mathbf{1 7}_{[2]}$ & $\mathbf{1 7}_{[2]}$ & $\mathbf{1 7}_{[2]}$ & $\mathbf{1}_{[2]}$ & $\mathbf{7}_{[2]}$ & $9_{[2]}$ & $9_{[2]}$ \\
0.5 & $m_{\pi}^{*}$ & $0_{[0]}$ & $17_{[2]}$ & $17_{[2]}$ & $0_{[0]}$ & $0_{[0]}$ & $0_{[0]}$ & $0_{[0]}$ \\
& $m_{C S}^{*}$ & $17_{[2]}$ & $17_{[0]}$ & $17_{[0]}$ & $1_{[2]}$ & $7_{[2]}$ & $97_{[0]}$ & $9_{[0]}$ \\
& $m_{W}^{*}$ & $17_{[2]}$ & $17_{[0]}$ & $17_{[0]}$ & $1_{[2]}$ & $7_{[2]}$ & $97_{[0]}$ & $9_{[0]}$ \\
& $m_{\pi}^{*}$ & $0_{[0]}$ & $17_{[2]}$ & $0_{[2]}$ & $0_{[0]}$ & $0_{[0]}$ & $0_{[0]}$ & $0_{[0]}$ \\
& $m_{C S}^{*}$ & $17_{[2]}$ & $17_{[0]}$ & $17_{[0]}$ & $1_{[2]}$ & $7_{[1]}$ & $97_{[0]}$ & $9_{[0]}$ \\
& $m_{W}^{*}$ & $17_{[1]}$ & $17_{[0]}$ & $17_{[0]}$ & $1_{[1]}$ & $7_{[1]}$ & $97_{[0]}$ & $9_{[0]}$ \\
\hline
\end{tabular}

Networks with $l_{\theta} \leq \frac{1}{N+1}$ are in bold

Parametrization: $\delta=0.5 ; \tau=10^{4} ; r=10^{6} ; l_{x}=0.5 ; \gamma_{\theta}=\gamma_{x}=10^{3} ; \varepsilon=10^{3} ; c=0$

The cumulative distribution function is denoted by $F(z)$ with $F(1)=1$. Following Calvó-Armengol and Zenou (2002), we restrict to symmetric density functions such that $f\left(l_{k}+z\right)=f\left(l_{k}-z\right)$ and $f\left(l_{k}+1 / N\right)=f\left(l_{k}\right)$. In other words, we are assuming that consumers are symmetrically distributed around firms and that the distribution of consumers between two adjacent firms is the same for any pair of firms considered. Moreover, we focus the analysis on two relevant polar cases where consumer 
Table 4 A comparison among profits, consumer surplus and welfare maximising degrees

\begin{tabular}{|c|c|c|c|c|c|c|c|c|}
\hline$l_{\theta}$ & & $\begin{array}{l}\delta=0 \\
N=20\end{array}$ & $\begin{array}{l}\delta=0.5 \\
N=20\end{array}$ & $\begin{array}{l}\delta=1 \\
N=20\end{array}$ & $\begin{array}{l}\delta=0 \\
N=4\end{array}$ & $\begin{array}{l}\delta=0 \\
N=10\end{array}$ & $\begin{array}{l}\delta=0 \\
N=10^{2}\end{array}$ & $\begin{array}{l}\delta=0 \\
N=10^{3}\end{array}$ \\
\hline \multirow[t]{3}{*}{0} & $m_{\pi}^{*}$ & $17_{[2]}$ & $\mathbf{0}_{[0]}$ & $\mathbf{0}_{[0]}$ & $\mathbf{1}_{[2]}$ & $7_{[2]}$ & $\mathbf{9 7}_{[2]}$ & $997_{[2]}$ \\
\hline & $m_{C S}^{*}$ & $17_{[2]}$ & $17_{[2]}$ & $17_{[2]}$ & $\mathbf{1}_{[2]}$ & $7_{[2]}$ & $97_{[2]}$ & $997_{[2]}$ \\
\hline & $m_{W}^{*}$ & $17_{[2]}$ & $17_{[2]}$ & $17_{[2]}$ & $\mathbf{1}_{[2]}$ & $7_{[2]}$ & $97_{[2]}$ & $997_{[2]}$ \\
\hline \multirow[t]{3}{*}{0.01} & $m_{\pi}^{*}$ & $17_{[2]}$ & $17_{[2]}$ & $17_{[2]}$ & $\mathbf{1}_{[2]}$ & $7_{[2]}$ & $97_{[2]}$ & $997_{[2]}$ \\
\hline & $m_{C S}^{*}$ & $17_{[2]}$ & $17_{[2]}$ & $17_{[2]}$ & $\mathbf{1}_{[2]}$ & $7_{[2]}$ & $97_{[2]}$ & $997_{[0]}$ \\
\hline & $m_{W}^{*}$ & $17_{[2]}$ & $17_{[2]}$ & $17_{[2]}$ & $\mathbf{1}_{[2]}$ & $7_{[2]}$ & $97_{[2]}$ & $997_{[0]}$ \\
\hline \multirow[t]{3}{*}{0.5} & $m_{\pi}^{*}$ & $17_{[2]}$ & $17_{[2]}$ & $17_{[2]}$ & $1_{[2]}$ & $7_{[2]}$ & $97_{[2]}$ & $997_{[2]}$ \\
\hline & $m_{C S}^{*}$ & $17_{[0]}$ & $17_{[0]}$ & $17_{[0]}$ & $1_{[1]}$ & $7_{[0]}$ & $97_{[0]}$ & $997_{[0]}$ \\
\hline & $m_{W}^{*}$ & $17_{[0]}$ & $17_{[0]}$ & $17_{[0]}$ & $1_{[1]}$ & $7_{[0]}$ & $97_{[0]}$ & $997_{[0]}$ \\
\hline \multirow[t]{3}{*}{1} & $m_{\pi}^{*}$ & $17_{[2]}$ & $0_{[2]}$ & $17_{[2]}$ & $1_{[2]}$ & $7_{[2]}$ & $97_{[2]}$ & $997_{[2]}$ \\
\hline & $m_{C S}^{*}$ & $17_{[0]}$ & $17_{[0]}$ & $17_{[0]}$ & $1_{[0]}$ & $7_{[0]}$ & $97_{[0]}$ & $997_{[0]}$ \\
\hline & $m_{W}^{*}$ & $17_{[0]}$ & $17_{[0]}$ & $17_{[0]}$ & $1_{[0]}$ & $7_{[0]}$ & $97_{[0]}$ & $997_{[0]}$ \\
\hline
\end{tabular}

Networks with $l_{\theta} \leq \frac{1}{N+1}$ are in bold

Parametrization: $\beta=0.5 ; \tau=10^{4} ; r=10^{6} ; l_{x}=0.5 ; \gamma_{\theta}=\gamma_{x}=10^{3} ; \varepsilon=10^{3} ; c=0$

distributions have $N$ peaks and $N$ troughs, whereas $\alpha=f\left(\frac{1}{2 N}\right)$ denotes the density of consumers at the midpoint between two neighbouring firms (see Figures 5 and 6). When $\alpha$ is low, consumers are located close to each firm's location. On the contrary, when $\alpha$ is high, the mass of consumers is located on the border between two adjacent firms. As Calvó-Armengol and Zenou (2002) point out, the two polar cases are the most realistic configurations from an economic point of view. In particular, the case with a small $\alpha$ can arise when firms advertise their products, shifting the distribution of consumers towards their own position. On the other hand, the case with high $\alpha$ can be explained with a sufficiently low level of transportation costs and high land prices for locations close to firms (for a deeper analysis of this aspect see Fujita and Thisse (1986)). Uniform distribution implies $f(z)=1$ for any $z$ on the Salop's circle, i.e $\alpha=1$.

Firm $i$ 's profits are now

$$
\pi_{i}=\int_{z_{i-1, i}}^{z_{i, i+1}}\left(p_{i}-c_{i}\right) f(z) d z-\gamma_{x} \frac{x_{i}^{2}}{2}-\gamma_{\theta} \frac{\theta_{i}^{2}}{2} .
$$

Deriving with respect to $p_{i}, x_{i}$ and $\theta_{i}$ we obtain respectively

$$
\begin{gathered}
p_{i}=\frac{F\left(z_{i, i+1}\right)-F\left(z_{i-1, i}\right)}{f\left(z_{i, i+1}\right)+f\left(z_{i-1, i}\right)} 2 \tau+c_{i}, \\
\left(p_{i}-c_{i}\right)\left[f\left(z_{i, i+1}\right) \frac{\partial z_{i, i+1}}{\partial \theta_{i}}-f\left(z_{i-1, i}\right) \frac{\partial z_{i-1, i}}{\partial \theta_{i}}\right]-\gamma_{\theta} \theta_{i}=0,
\end{gathered}
$$




$$
\left[1+(1-\delta) \delta x_{i}^{\delta-1} l_{x}\left(\sum_{k \in N_{i}} x_{k}\right)^{(1-\delta)}\right] \int_{z_{i, i+1}}^{z_{i-1, i}} f(z) d z-\gamma_{x} x_{i}=0 .
$$

It is now possible to summarize the results in the following Proposition.

Proposition 8 Under the hypothesis of non-uniform and symmetric consumer distribution the results in Propositions 1-5 hold, whereas the level of prices changes.

Proof By symmetry we know that $p_{i}=p_{i-1}=p_{i+1}=p^{*}, r_{i}=r_{i-1}=r_{i+1}=r^{*}$, $z_{i-1, i}=l_{i}-\frac{1}{2 N}, z_{i, i+1}=l_{i}+\frac{1}{2 N}$ and $f\left(z_{i-1, i}\right)=f\left(z_{i, i+1}\right)=\alpha, F\left(z_{i, i+1}\right)-F\left(z_{i-1, i}\right)=\frac{1}{N}$. Then, condition (33) can be rewritten as

$$
p^{*}=\frac{\tau}{\alpha N}+c_{i}
$$

whereas it is straightforward to show that conditions (34) and (35) boil down to (12) and (13), i.e. remain unchanged confirming the same results of the benchmark model.

\section{Fixed prices}

Assuming $p_{i}=p_{i+1}=p_{i-1}=\hat{p}$ and solving the model we obtain the following symmetric optimal level of $R \& D$ investments:

$$
\begin{gathered}
\theta^{*}=\left[\frac{\left(\hat{p}-c^{*}\right) \frac{\alpha \beta \varepsilon}{\tau}\left(1+l_{\theta} m\right)^{\beta-1}\left(1-\frac{l_{\theta}}{2} s\right)}{\gamma_{\theta}}\right]^{\frac{1}{2-\beta}} \\
x^{*}=\frac{1}{\gamma_{x} N}\left[1+(1-\delta) \delta l_{x} m^{1-\delta}\right]
\end{gathered}
$$

where $c^{*}=c-\frac{1}{\gamma_{x} N}\left[1+(1-\delta) \delta l_{x} m^{1-\delta}\right]\left[1+(1-\delta) l_{x} m^{1-\delta}\right]$.

The maximised firm's profit is $\pi^{*}=\left(\hat{p}-c^{*}\right) \frac{1}{N}-\gamma_{x} \frac{\left(x^{*}\right)^{2}}{2}-\gamma_{\theta} \frac{\left(\theta^{*}\right)^{2}}{2}$ from which we obtain the following result.

Proposition 9 In a model with fixed prices, endogenous product and process innovation the following statements hold:

1. firm's profits are maximised with the complete network, i.e. $m^{*}=(N-3)_{[2]}$;

2. social welfare $W=\pi^{*} N+C S$ is maximised with the complete network if $l_{\theta} \leq \frac{1}{N+1}$. 
Proof First, it is straightforward to show that $\frac{\partial \pi^{*}}{\partial \bar{m}} \geq 0$ and $\frac{\partial \pi^{*}}{\partial s} \geq 0 \forall \bar{m}, s$ and for any admissible set of parameters. Second, we can build directly from the proof of Proposition 4. Observe that $\frac{\partial C S}{\partial \bar{m}}=\frac{\partial r^{*}}{\partial \bar{m}} \geq 0 \forall \bar{m}, s$ and $\frac{\partial C S}{\partial s}=\frac{\partial r^{*}}{\partial s} \geq 0$ if $l_{\theta} \leq \frac{1}{N+1}$.

\section{References}

Adner, R., \& Kapoor, R. (2010). Value creation in innovation ecosystems: howthe structure of technological interdependence affects firm performance in new technology generations. Strategic Management Journal, 31, 306-333.

Adner, R., \& Levinthal, D. (2001). Demand heterogeneity and technology evolution: implications for product and process innovation. Management Science, 47(5), 611-628.

Athey, S., \& Schmutzler, A. (1995). Product and process flexibility in an innovative environment. Rand Journal of Economics, 26(4), 557-574.

Baumol, W. J. (2001). When is inter-firm coordination beneficial? The case of innovation. International Journal of Industrial Organization, 19, 727-737.

Bloch, F. (1995). Endogenous structures of associations in oligopolies. RAND Journal of Economics, 26(3), 537-556.

Brekke, K., Nuscheler, R., \& Straume, O. R. (2006). Quality and location choice under price regulation. Journal of Economics and Management Strategy, 15(1), 207-227.

Buechel, B., \& Hellmann, T. (2012). Under-connected and over-connected networks: the role of externalities in strategic network formation. Review of Economic Design, 16, 71-87.

Calvó-Armengol, A., \& Zenou, Y. (2002). The importance of distribution of consumers in horizontal product differentiation. Journal of Regional Science, 42(4), 793-803.

Chen, Y., \& Riordan, M. (2007). Price and variety in the spokes model. Economic Journal, 56(3), 553-577.

Correani, L., \& Di Dio, F. (2017). A Note on Link Formation and Network Stability in a Hotelling Game. Operations Research Letters, 45, 289-292.

Correani, L., \& Di Dio, F. (2019). Collaboration networks in a Hotelling game. Economics Bulletin, $39(1), 1-16$.

Correani, L., Garofalo, G., \& Pugliesi, S. (2014). R \& D cooperation in regular networks with endogenous absorptive capacity. Review of Network Economics, 13(2), 191-226.

D’Aspremont, C., \& Jaquemine, A. (1988). Cooperative and non Cooperative R\&D in duopoly with spillovers. American Economic Review, 78(5), 1133-1137.

Deroian, F., \& Gannon, F. (2006). Quality-improving alliances in differentiated oligopoly. International Journal of Industrial Organization, 24, 629-637.

Economides, N. (1993). Quality variations in the circular model of variety-differentiated products. Regional Science and Hurban Economics, 23, 235-257.

Falk, R. (2007). Measuring the effects of public support schemes on firms innovation activities. Survey evidence from Austria. Research Policy, 36(5), 665-679.

Fujita, M., \& Thisse, J. F. (1986). Spatial competition with a land market: Hotelling and Von Thunen unified. Review of Economic Studies, 53, 819-841.

Goyal, S., \& Joshi, S. (2003). Networks of collaboration in oligopoly. Games and Economic Behaviour, $43,57-85$.

Goyal, S., \& Moraga-Gonzalez, J. L. (2001). R \& D networks. The RAND Journal of Economics, 32(4), 686-707.

Goyal, S., Moraga-González, J. L., \& Konovalov, A. (2008). Hybrid R \& D. Journal of the European Economic Association, 6(6), 1309-1338.

Grunfeld, L. A. (2003). Meet me halfway but don't rush: Absorptive capacity and strategic R \& D investment revisited. International Journal of Industrial Organization, 21, 1091-1109.

Heikkinen, T. (2014). A spatial economic model under network externalities: Symmetric equilibrium and efficiency. Operational Research, 14(1), 89-111. 
Jaffe, A. (1986). Technological opportunities and spillovers of R \& D: Evidence from firms' patents, profit and market value. American Economic Review, 76(5), 984-1001.

Kamien, M. I., \& Zang, I. (2000). Meet me halfway: Research joint ventures and absorptive capacity. International Journal of Industrial Organization, 18, 995-1012.

Klepper, S. (1996). Entry, exit and innovation over the product life cycle. American Economic Review, $86,562-583$.

Lambertini, L., \& Mantovani, A. (2009). Process and product innovation by a multiproduct monopolist: A dynamic approach. International Journal of Industrial Organization, 27, 508-518.

Leahy, D., \& Neary, P. (1997). Public policy towards R \& D in oligopolistic industries. The American Economic Review, 87(4), 642-662.

Leahy, D., \& Neary, P. (2007). Absorptive capacity, R \& D spillovers and public policy. International Journal of Industrial Organization, 25, 1089-1108.

Lopez, A. (2008). Determinants of R \& D cooperation: Evidence from Spanish manufacturing firms. International Journal of Industrial Organization, 26, 113-136.

Lukkonen, T. (1998). The difficulties in assessing the impact of EU framework programmes. Research Policy, 27(6), 599-610.

Mantovani, A., \& Ruiz-Aliseda, F. (2016). Equilibrium innovation ecosystems: The dark side of collaborating with complementors. Management Science, 62(2), 534-549.

Martin, S. (1995). R \& D joint ventures and tacit product market collusion. European Journal of Political Economy, 11(4), 733-741.

Motta, M. (1992). Cooperative R\&D and vertical product differentiation. International Journal of Industrial Organization, 10(4), 643-661.

Okumura, Y. (2012). Spatial competition and collaboration networks. International Journal of Game Theory, 41, 455-472.

Paier, M., \& Scherngell, T. (2011). Determinants of collaboration in European R \& D networks: Empirical evidence from a discrete choice model. Industry and Innovation, 18(1), 89-104.

Reggiani, C. (2014). Spatial price discrimination in the spoke model. Journal of Economics and Management Strategy, 23(3), 628-649.

Salop, S. (1979). Monopolistic competition with outside goods. Bell Journal of Economics, 10, 141-156.

Suzumura, K. (1992). Cooperative and non cooperative R\&D in a oligopoly with spillovers. American Economic Review, 82(5), 1307-1320.

Symeonidis, G. (2003). Comparing Cournot and Bertrand equilibria in a differentiated duopoly with product R \& D. International Journal of Industrial Organization, 21, 39-55.

Tomasello, M. V., Napoletano, M., Garas, A., \& Schweitzer, F. (2016). The rise and fall of R \& D networks. Industrial and Corporate Change, 26(4), 617-646.

Vonortas, N. S. (1994). Inter-firm cooperation with imperfectly appropriable research. International Journal of Industrial Organization, 12, 413-435.

Yi, S., \& Shin, H. (2000). Endogenous formation of research coalitions with spillovers. International Journal of Industrial Organization, 18(2), 229-256.

Publisher's Note Springer Nature remains neutral with regard to jurisdictional claims in published maps and institutional affiliations. 